\title{
Investigation of Fe-Doped Graphitic Carbon Nitride-Silver Tungstate as a Ternary Visible Light Active Photocatalyst
}

\author{
Eid H. Alosaimi, ${ }^{1}$ Nadia Azeem, ${ }^{2}$ Noor Tahir, ${ }^{2}$ Asim Jilani ${ }^{1},{ }^{3}$ Muhammad Zahid $\left(\mathbb{D},{ }^{2}\right.$ \\ Salman. S. Alharthi, ${ }^{4}$ Javed Iqbal $\mathbb{D},{ }^{2}$ Muhammad Yaseen, ${ }^{5}$ Zulfiqar Ahmad Rehan $\mathbb{D}^{6}$, \\ and Imran Shahid ${ }^{7}{ }^{7}$ \\ ${ }^{1}$ Department of Chemistry, College of Science, University of Bisha, P.O. Box 511, Bisha 61922, Saudi Arabia \\ ${ }^{2}$ Department of Chemistry, University of Agriculture, Faisalabad 38040, Pakistan \\ ${ }^{3}$ Center of Nanotechnology, King Abdulaziz University, Jeddah, Saudi Arabia \\ ${ }^{4}$ Department of Chemistry, College of Science, Taif University, P.O. Box 11099, Taif 21944, Saudi Arabia \\ ${ }^{5}$ Department of Physics, University of Agriculture Faisalabad, Faisalabad, Pakistan \\ ${ }^{6}$ Department of Polymer Engineering, National Textile University Faisalabad, Pakistan \\ ${ }^{7}$ Environmental Science Centre, Qatar University, Doha, P.O. Box 2713, Qatar
}

Correspondence should be addressed to Muhammad Zahid; rmzahid@uaf.edu.pk and Zulfiqar Ahmad Rehan; zarehan@ntu.edu.pk

Received 3 August 2021; Accepted 13 October 2021; Published 15 November 2021

Academic Editor: Marcelino Maneiro

Copyright (C) 2021 Eid H. Alosaimi et al. This is an open access article distributed under the Creative Commons Attribution License, which permits unrestricted use, distribution, and reproduction in any medium, provided the original work is properly cited.

\begin{abstract}
The rapid population growth and economic development have largely contributed to environmental pollution. Various advanced oxidation processes have been used as the most viable solution for the reduction of recalcitrant pollutants and wastewater treatment. Heterogeneous photocatalysis is one of the broadly used technologies for wastewater treatment among all advanced oxidation processes. Graphitic carbon nitride alone or in combination with various other semiconductor metal oxide materials acts as a competent visible light active photocatalyst for the removal of recalcitrant organic pollutants from wastewater. Rational designing of an environment-friendly photocatalyst through a facile synthetic approach encounters various challenges in photocatalytic technologies dealing with semiconductor metal oxides. Doping in $\mathrm{g}_{-} \mathrm{C}_{3} \mathrm{~N}_{4}$ and subsequent coupling with metal oxides have shown remarkable enhancement in the photodegradation activity of $\mathrm{g}_{-} \mathrm{C}_{3} \mathrm{~N}_{4}$-based nanocomposites owing to the modulation in $\mathrm{g}-\mathrm{C}_{3} \mathrm{~N}_{4}$ bandgap structuring and surface area. In the current study, a novel ternary Fe-doped g- $\mathrm{C}_{3} \mathrm{~N}_{4} / \mathrm{Ag}_{2} \mathrm{WO}_{4}$ visible light active photocatalyst was fabricated through an ultrasonic-assisted facile hydrothermal method. Characterization analysis included SEM analysis, FTIR, XRD, XPS, and UV-Visible techniques to elucidate the morphology and chemical structuring of the as-prepared heterostructure. The bandgap energies were assessed using the Tauc plot. The ternary nanocomposite (Fe-CN-AW) showed increased photodegradation efficiency (97\%) within 120 minutes, at optimal conditions of $\mathrm{pH}=8$, catalyst dose $=50 \mathrm{mg} / 100 \mathrm{ml}$, an initial $\mathrm{RhB}$ concentration of $10 \mathrm{ppm}$, and oxidant dose $5 \mathrm{mM}$ under sunlight irradiation. The enhanced photodegradation of rhodamine B dye by ternary Fe-CN-AW was credited to multielectron transfer pathways due to insertion of a Fe dopant in graphitic carbon nitride and subsequent coupling with silver tungstate. The data were statistically assessed by the response surface methodology.
\end{abstract}

\section{Introduction}

Water constitutes a major part of the planet Earth. Almost $98 \%$ of this water is seawater and cannot be used for drinking purposes because of the high salt content. Approximately $2 \%$ of water is drinkable [1]. Extensive contamination due to global industrialization, commercialization, and agricultural practices has led to the release of organic pollutants that immensely polluted the freshwater reservoirs. Hence, water pollution has emerged as one of the foremost global 
environmental challenges. Wastewater discharged from industries and various human activities has caused perilous environmental impacts. An alarming population is suffering every day due to the unavailability of clean drinking water. This gross negligence from various industrial units for releasing wastewater without any treatment into freshwater streams has posed grave threats to human health [2].

Previously, conventional methods such as activated carbon adsorption, filtration, extraction, oxidation, ultrafiltration, electrolysis, chemical oxidation, and biological treatment were used which usually caused incomplete mineralization of pollutants. The shortcomings of these conventional methods were overcome with progressive research in the development of various advanced oxidation technologies. Advanced oxidation processes (AOPs) were firstly utilized in the early 1980s for water treatment and purification. In wastewater treatment, hydroxyl radicals act as strong oxidizing agents, breaking down complex organic pollutants and converting them into less harmful products [3]. Advanced oxidation processes include ozone, Fenton, heterogeneous photocatalysis, sonolysis, catalytic wet air oxidation, and electrochemical oxidation. Sometimes, these processes can combine to produce strong oxidizing radicals that attack any pollutant in the water without distinction and convert them into nonharmful compounds such as carbon dioxide, water, and inorganic ions. AOPs can make use of different semiconductor photocatalysts such as binary or ternary metal oxides and carbon-based support materials [4].

Heterogeneous photocatalysis based on metal-oxidebased semiconductor materials has been employed widely for the degradation of recalcitrant pollutants. Among these conventional semiconductor materials, a new carbon-based photocatalyst graphitic carbon nitride $\left(\mathrm{g}-\mathrm{C}_{3} \mathrm{~N}_{4}\right)$ is being investigated for the fabrication of heterostructures for enhanced degradation under sunlight irradiation. Graphitic carbon nitride is an excellent visible light active and twodimensional polymeric compound that is highly stable chemically and thermally and has a tunable bandgap from $1.7 \mathrm{eV}$ to $2.8 \mathrm{eV}$ [5]. The medium bandgap range of $\mathrm{g}-\mathrm{C}_{3} \mathrm{~N}_{4}$, its chemical and thermal stability, polymeric structure, and simple synthesis methods make it an excellent visible light active photocatalyst and a good semiconductor material for the conversion of solar energy [6]. But, the catalytic performance of $\mathrm{g}-\mathrm{C}_{3} \mathrm{~N}_{4}$ alone is hindered because of some limitations such as fast charge carrier recombination [7]. The limitations due to fast $\mathrm{e}^{-} / \mathrm{h}^{+}$recombination of $\mathrm{g}-\mathrm{C}_{3} \mathrm{~N}_{4}$-based photocatalysts can be addressed using various strategies including doping and coupling with metal oxides [8]. The photoresponse of $\mathrm{g}-\mathrm{C}_{3} \mathrm{~N}_{4}$ can be enhanced through doping various transition metals including $\mathrm{Fe}, \mathrm{Mn}, \mathrm{Cu}$. $\mathrm{Co}, \mathrm{Ni}$, and Mo and coupling with other metal oxides to enhance visible light response [9]. g- $\mathrm{C}_{3} \mathrm{~N}_{4}$ support-based photocatalysts are now frequently used in various applications of heterogeneous photocatalysis because these photocatalysts profoundly satisfy environmental requirements of green photocatalysis and the formation of hybrid structures [10]. Doping of a transition metal in $\mathrm{g}-\mathrm{C}_{3} \mathrm{~N}_{4}$ lattices alters the physical and chemical properties and enhances the visible light absorption response for degradation of pollutants by changing the structure and surface area of $g-\mathrm{C}_{3} \mathrm{~N}_{4}$ [11]. Iron (Fe) has proved to be an excellent candidate for doping with graphitic carbon nitride because of its existence in various oxidation states. Insertion of Fe into $\mathrm{g}-\mathrm{C}_{3} \mathrm{~N}_{4}$ has shown enhancement in electrochemical conductivity and light absorption ability [12]. Silver tungstate $\left(\mathrm{Ag}_{2} \mathrm{WO}_{4}\right)$ is a ternary semiconductor metal oxide having a bandgap between $2.8 \mathrm{eV}$ and $3.1 \mathrm{eV}$. This ternary metal oxide has been gaining attention because of its better light-harvesting ability and photoluminescence characteristics. Silver tungstate (AW) is functionalized by coupling with other photoactive materials to increase the photoresponse and improve its stability [13].

Hence, it is the necessity of time to synthesise such visible light-reactive ternary systems that are more efficient than those utilized in conventional methods for wastewater remediation. This work was proposed for the investigation of rhodamine $\mathrm{B}$ $(\mathrm{RhB})$ dye degradation by ternary Fe-doped $\mathrm{g}-\mathrm{C}_{3} \mathrm{~N}_{4} / \mathrm{Ag}_{2} \mathrm{WO}_{4}$ nanocomposite. To the best of our knowledge, this composite has not been studied earlier for the photodegradation of organic pollutants. Iron-doped graphitic carbon nitride was coupled with silver tungstate in which $\mathrm{WO}_{4}$ has attracted attention due to high chemical and thermal stability and has reasonable electron transfer behavior. $\mathrm{g}-\mathrm{C}_{3} \mathrm{~N}_{4}$ and $\mathrm{WO}_{4}$ have almost similar bandgaps [14]. The degradation of rhodamine $\mathrm{B}$ $(\mathrm{RhB})$ dye was analyzed over Fe/g- $\mathrm{C}_{3} \mathrm{~N}_{4}(\mathrm{Fe}-\mathrm{CN}), \mathrm{g}-\mathrm{C}_{3} \mathrm{~N}_{4} /$ $\mathrm{Ag}_{2} \mathrm{WO}_{4}(\mathrm{CN}-\mathrm{AW})$, and Fe-doped g- $\mathrm{C}_{3} \mathrm{~N}_{4}-\mathrm{Ag}_{2} \mathrm{WO}_{4} /(\mathrm{Fe}-\mathrm{CN}-$ $\mathrm{AW})$. The photocatalytic activity of these three catalysts towards RhB degradation was studied under sunlight. The effect of various parameters, for example, $\mathrm{pH}$, oxidant dose, irradiation time, and catalyst dose, was optimized. The interaction of various parameters was studied using the response surface methodology (RSM). The catalysts were characterized by Fourier transform infrared spectroscopy (FTIR), scanning electron microscopy, X-ray diffraction (XRD), XPS, and UVVis techniques.

\section{Experimental}

2.1. Regents and Materials. Melamine $\left(\mathrm{C}_{6} \mathrm{H}_{6} \mathrm{~N}_{6}>99 \%\right)$ and silver nitrate $\left(\mathrm{AgNO}_{3} ; 99.9 \%\right.$ purity) were purchased from DAEJUNG, sodium tungstate dihydrate $\left(\mathrm{Na}_{2} \mathrm{WO}_{4} \cdot 2 \mathrm{H}_{2} \mathrm{O}\right.$; 97\% purity) and ethanol $\left(\mathrm{C}_{2} \mathrm{H}_{5} \mathrm{OH} ; 95.6 \%\right.$ purity $)$ were purchased from UNI-Chem, ferric chloride hexahydrate $\left(\mathrm{FeCl}_{3} \cdot 6 \mathrm{H}_{2} \mathrm{O}\right.$; > $99 \%$ purity) and hydrogen peroxide $\left(\mathrm{H}_{2} \mathrm{O}_{2}\right.$; $35 \%$ purity) were purchased from Merck, sodium hydroxide (NaOH; 98-100.5\% purity) and hydrochloric acid ( $\mathrm{HCl} ; 35 \%$ purity) were purchased from Sigma-Aldrich, and rhodamine $\mathrm{B}\left(\mathrm{C}_{28} \mathrm{H}_{31} \mathrm{ClN}_{2} \mathrm{O}_{3} ; 92 \%\right.$ purity $)$ was purchased from PubChem. Analytical-grade chemicals and solvents were used in all experiments without additional purification. During the whole experimental study, distilled water was utilized.

2.2. Synthesis of $g-C_{3} N_{4}$. Synthesis of $g-C_{3} \mathrm{~N}_{4}$ was carried out in a muffle furnace (AB UMEGA SNOL-3/1100) by condensation of melamine. The $5 \mathrm{~g}$ mass of melamine was measured and placed in a ceramic crucible, covered 
completely, and then, placed in a muffle furnace. Melamine was heated at $20^{\circ} \mathrm{C}$ per minute for about 2 hours, and the temperature gradually rose until it reached the final temperature. The terminal temperatures were $500^{\circ} \mathrm{C}, 550^{\circ} \mathrm{C}$, and $600^{\circ} \mathrm{C}$. Then, crucibles containing the sample were chilled to $25^{\circ} \mathrm{C}$ temperature, and the product formed was ground by using a pestle and mortar [15].

2.3. Synthesis of $C N-A W$. To prepare the $\mathrm{Ag}_{2} \mathrm{WO}_{4} / \mathrm{g}-\mathrm{C}_{3} \mathrm{~N}_{4}$ composite, sodium tungstate $(0.1 \mathrm{mmol} / \mathrm{L})$ and silver nitrate $(0.2 \mathrm{mmol})$ were added to $40 \mathrm{ml}$ deionized $\mathrm{H}_{2} \mathrm{O}$. To the abovementioned mixture, $1 \mathrm{~g}$ of previously prepared g- $\mathrm{C}_{3} \mathrm{~N}_{4}$ was added. Then, the whole mixture was sonicated to get a homogenous solution at a temperature of $20^{\circ} \mathrm{C}$ for about half an hour. This uniform mixture was gradually poured into a $50 \mathrm{ml}$ capacity autoclave having a Teflon-line. After transferring the mixture into the autoclave, it was heated at $180^{\circ} \mathrm{C}$ for 12 hours in an electric oven. After that, it was filtered and cleaned with distilled $\mathrm{H}_{2} \mathrm{O}$ until its $\mathrm{pH}$ became neutral. It was dried at $60^{\circ} \mathrm{C}$ for 5 hours after filtration to obtain the final product, as shown in Figure 1(b) [16].

2.4. Synthesis of $\mathrm{Fe}-\mathrm{CN}$. Iron-doped graphitic carbon nitride (Fe-CN) was synthesised by a simple process in which $0.5 \mathrm{M}$ $\left(\mathrm{FeCl}_{3} .6 \mathrm{H}_{2} \mathrm{O}\right)$ was mixed in $50 \mathrm{ml}$ ethanol. Then, $0.5 \mathrm{~g}$ of graphitic carbon nitride was dissolved into the abovementioned solution with constant stirring and stirred magnetically for two hours at room temperature. The suspension obtained after stirring was then centrifuged at 6000 revolutions per minute for fifteen minutes, and distilled water, as well as acetone, was used to wash it several times until it became neutral. Then, it was dried at room temperature, as shown in Figure 1(c) [17].2.5. Hydrothermal Synthesis of Ternary Fe-CN-AW.

A hydrothermal method was used for the synthesis of the ternary iron-doped graphitic carbon nitride/silver tungstate (Fe-CN-AW) nanocomposite. In the first step, $2.5 \mathrm{mmol}$ $(0.28 \mathrm{~g})$ of sodium tungstate $\left(\mathrm{Na}_{2} \mathrm{WO}_{4} \cdot 2 \mathrm{H}_{2} \mathrm{O}\right)$ was dissolved completely in $40 \mathrm{ml}$ distilled water with magnetic stirring. Another solution was made in which $5 \mathrm{mmol}(0.29 \mathrm{~g})$ of $\mathrm{AgNO}_{3}$ was added to $20 \mathrm{ml}$ of distilled $\mathrm{H}_{2} \mathrm{O}$. Both solutions were mixed slowly under continuous stirring. The previously prepared Fe-doped graphitic carbon nitride ( 2 mol \%) was ultrasonically dispersed in $30 \mathrm{ml}$ of distilled water and added to solution A dropwise. After that, the whole suspension was stirred magnetically for four hours at $25^{\circ} \mathrm{C}$ temperature till a uniform solution was obtained. The resultant mixture was transferred into an autoclave reactor lined with Teflon at an elevated temperature of $180^{\circ} \mathrm{C}$ for about 24 hours. The final product was rinsed three times with ethanol and distilled water. Employing an electric oven, the sample was later dried for about 12 hours at $60^{\circ} \mathrm{C}$. Figure $1(\mathrm{~d})$ explains the stepwise synthesis of ternary Fe-CNAW heterojunction.

2.5. Characterization and Equipment. The phase identification, crystalline nature, and crystal structure of $\mathrm{Fe}-\mathrm{CN}, \mathrm{CN}$ $\mathrm{AW}$, and ternary Fe-doped $\mathrm{CN}-\mathrm{AW}$ were analyzed by powder
XRD (XRD-PANalytical-Xpert pro DY 3805) containing a Ni$\beta$ filter and $\mathrm{Cu}-\mathrm{K} \alpha$ radiations $(1.54059 \AA)$, over a range from $10^{\circ}$ to $80^{\circ}$ of $2 \theta$ values. The identification of various functional groups was recorded using an FTIR spectrophotometer (Agilent Technologies) in the transmission mode, between $650 \mathrm{~cm}^{-1}$ and $4000 \mathrm{~cm}^{-1}$. A scanning electron microscope (SEM-JEOL/EO Japan JSM-5910) was used for observing the morphology of all samples. The surface chemical states were analyzed using XPS (XPS system Escalab 250, Thermo Scientific Uk). The optical and photocatalytic properties of doped and undoped nanocomposites were analyzed utilizing a double-beam UV-Vis (Cecil CE 7200) spectrophotometer.

2.6. Photocatalytic Degradation Evaluation. The photocatalytic degradation of rhodamine B dye was estimated under UV and sunlight irradiation. Different feasibility experiments were initially performed to check the activity of the ternary photocatalyst. For attaining a stage of adsorption-desorption equilibrium between the catalyst surface and pollutant molecule, the RhB solution was placed for about half an hour in the dark with continuous stirring on an orbital shaker. The adsorption was measured by taking $5 \mathrm{ml}$ solution and taking absorbance. The adsorption rate usually starts decreasing after 30 minutes. The whole setup was then brought under sunlight irradiation, and the photodegradation process was started. Similar experiments were performed under ultraviolet radiation as well. Optimization of various parameters for $\mathrm{RhB}$ degradation was performed, including $\mathrm{pH}(2-9)$, initial $\mathrm{RhB}$ concentration $(10-50 \mathrm{ppm})$, oxidant dose $(2-15 \mathrm{mM})$, catalyst dose (10-100 mg), and time of irradiation (20-120 minutes). A UV-Vis spectrophotometer was used to check absorbance at $554 \mathrm{~nm}$ by taking a $10 \mathrm{ml}$ clear $\mathrm{RhB}$ solution obtained after separation of the composite through centrifugation. The degradation process was also studied in the absence of light by placing a beaker of dye solution in the dark. The blank experiment performed without a catalyst and light revealed no distinct photocatalytic activity, signifying that the reaction was driven by the photocatalytic process over the photocatalytic process of light. The following formula was used to calculate $\%$ degradation:

$$
\% \text { degradation }=1-\frac{A}{A o} \times 100,
$$

where Ao is described as the initial absorbance and A is the calculated final absorbance after a performed reaction in sunlight. A light meter (HS1010 A) and solar power meter (SM206) were used for measuring the brightness and intensity of sunlight. The measured average light intensity was $1200 \mathrm{~W} / \mathrm{m}^{2}$, and the brightness was measured between the range of $88,000 \pm 2000$ Lux. The degradation reaction was carried out in the afternoon when the sky was bright and clear. The intensity of the UV light was $254 \mathrm{~nm}$, and the experiment was performed in a UV chamber ZM144 (ZAM ZAM Microtechnologies). The catalyst's reusability was examined by recycling ternary composites by washing with distilled water, drying, and then, reusing till five cycles under sunlight, each at their optimum conditions with $10 \mathrm{ppm} \mathrm{RhB}$ solution prepared fresh each time. 


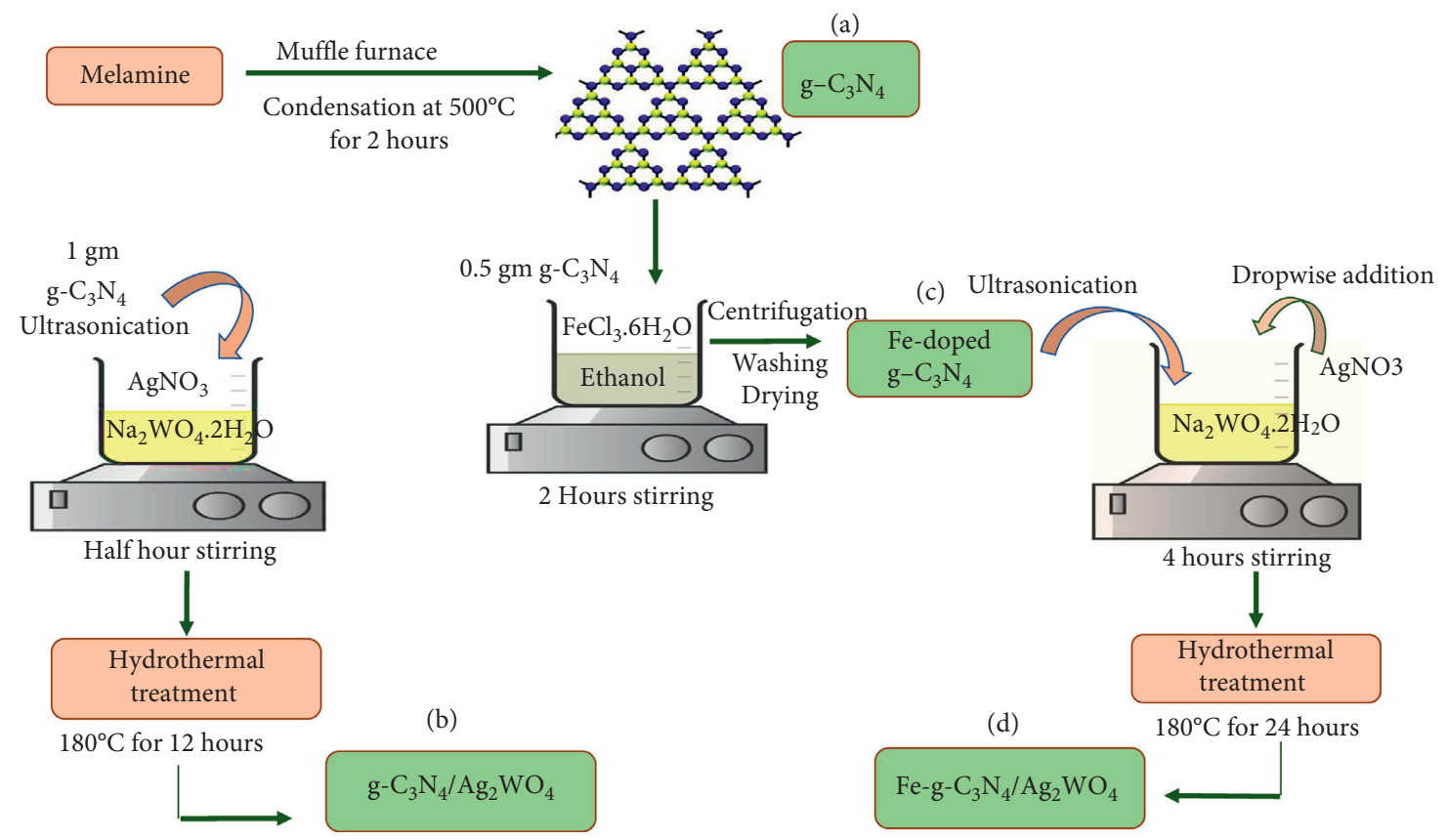

Figure 1: Schematic illustration of (a) g- $\mathrm{C}_{3} \mathrm{~N}_{4}$, (b) $\mathrm{g}-\mathrm{C}_{3} \mathrm{~N}_{4}-\mathrm{Ag}_{2} \mathrm{WO}_{4}$, (c) Fe-g- $\mathrm{C}_{3} \mathrm{~N}_{4}$, and (d) Fe-g- $\mathrm{C}_{3} \mathrm{~N}_{4} / \mathrm{Ag}_{2} \mathrm{WO}_{4}$ heterojunctions.

\section{Results and Discussion}

3.1. FTIR Analysis. The FTIR analysis was recorded between the range of $500 \mathrm{~cm}^{-1}$ and $4500 \mathrm{~cm}^{-1}$ for the determination of various functional groups present on the surface of the ternary composite. Graphitic carbon nitride was synthesised under varying temperature conditions. FTIR spectra showed all the characteristic transmittance peaks of $\mathrm{g}-\mathrm{C}_{3} \mathrm{~N}_{4}$ confirming the synthesis of graphitic carbon nitride, without any prominent change at different temperatures, as shown in Figure 2(f). The broad absorption band of pristine $g-\mathrm{C}_{3} \mathrm{~N}_{4}$ can be seen in all the samples synthesised at various temperatures. The bands beyond $3000 \mathrm{~cm}^{-1}$ up to $3300 \mathrm{~cm}^{-1}$ are due to $\mathrm{N}-\mathrm{H}$ bond stretching vibration resulting from partial condensation of amino acids. The series of peaks appearing between $1200 \mathrm{~cm}^{-1}$ and $1620 \mathrm{~cm}^{-1}$ shows the stretching vibrations of $\mathrm{CN}$ heterocycles. At $500^{\circ} \mathrm{C}$, two bands were seen at $1598 \mathrm{~cm}^{-1}$ and $1395 \mathrm{~cm}^{-1}$. The peaks at $1228 \mathrm{~cm}^{-1}$ and $1395 \mathrm{~cm}^{-1}$ matched well with $\mathrm{g}-\mathrm{C}_{3} \mathrm{~N}_{4}$. At $550^{\circ} \mathrm{C}$ in the spectrum, N-H stretching vibration was observed by a peak at $3151 \mathrm{~cm}^{-1}$ while the vibration bands from $1200 \mathrm{~cm}^{-1}$ and $1800 \mathrm{~cm}^{-1}$ are related to $\mathrm{g}-\mathrm{C}_{3} \mathrm{~N}_{4}$. The spectrum corresponds to $550^{\circ} \mathrm{C}$ and at $15^{\circ} \mathrm{C} / \mathrm{min}$ has bands in the range from $1300 \mathrm{~cm}^{-1}$ to $1828 \mathrm{~cm}^{-1}$, representing vibrations of $\mathrm{C}-\mathrm{N}$ bonds. The FTIR spectrum of Fe-CN, CN-AW, and Fe-CNAW was compared and shown in Figures 2(c)-2(e), respectively. In the Fe-CN spectrum, a broad peak appeared at $3078 \mathrm{~cm}^{-1}$ which is a distinctive peak of the $\mathrm{N}-\mathrm{H}$ group. It is due to the vibrational mode of the residual $\mathrm{N}-\mathrm{H}$ group of graphitic carbon nitride. The vibrational mode of the $\mathrm{C}-\mathrm{N}$ band was shown by a range of peaks from $1200 \mathrm{~cm}^{-1}$ to $1600 \mathrm{~cm}^{-1}$. The peaks appearing at $1234 \mathrm{~cm}^{-1}, 1385 \mathrm{~cm}^{-1}$, and $1578 \mathrm{~cm}^{-1}$ related to the $\mathrm{CN}$ heterocycles corresponding to $\mathrm{C}-\mathrm{NH}-\mathrm{C}, \mathrm{C}-\mathrm{N}$, and $\mathrm{C}=\mathrm{N}$ confirm fabrication of graphitic carbon nitride in all samples [18]. A small additional peak at $2145 \mathrm{~cm}^{-1}$ indicates the $\mathrm{Fe}^{3+}$ dopant's existence in a polymeric network of $\mathrm{g}-\mathrm{C}_{3} \mathrm{~N}_{4}$ [19]. A peak near $807 \mathrm{~cm}^{-1}$ shows the occurrence of a triazine ring of aromatic nature. The prominent and distinctive $\mathrm{g}-\mathrm{C}_{3} \mathrm{~N}_{4}$ bands seem to shift towards lower wavenumbers, and the intensity of FTIR spectra peaks is decreased in the Fe-CN-AW composite. This shift indicates the weakening of $\mathrm{C}-\mathrm{N}$ and $\mathrm{C}=\mathrm{N}$ as a result of interaction between $\mathrm{g}-\mathrm{C}_{3} \mathrm{~N}_{4}$ and $\mathrm{Fe}$ [17]. In the $\mathrm{CN}-\mathrm{AW}$ composite spectrum, a broad peak was presented at $3153 \mathrm{~cm}^{-1}$ which is owing to the $\mathrm{N}-\mathrm{H}$ band stretching mode [20]. The peak at $2381 \mathrm{~cm}^{-1}$ is owed to amide linkages, and carbonyl group presence is represented by a peak at $1600 \mathrm{~cm}^{-1}$ [21]. There is a range of peaks from $1200 \mathrm{~cm}^{-1}$ to $1600 \mathrm{~cm}^{-1}$ similar to the Fe-CN spectrum which is due to the IR active vibrational mode of the $\mathrm{C}-\mathrm{N}$ bond. Two peaks at $739 \mathrm{~cm}^{-1}$ and $630 \mathrm{~cm}^{-1}$ show $\mathrm{O}-\mathrm{W}-\mathrm{O}$ and $\mathrm{W}-\mathrm{O}-\mathrm{W}$ groups that are a special feature of tetrahedral tungstates. All the peaks present in pure $\mathrm{g}-\mathrm{C}_{3} \mathrm{~N}_{4}$ remain intact in ternary the $\mathrm{Fe}-\mathrm{g}-\mathrm{C}_{3} \mathrm{~N}_{4} / \mathrm{Ag}_{2} \mathrm{WO}_{4}$ composite.

3.2. XRD Analysis. To determine the various phases and crystal structure of $\mathrm{CN}, \mathrm{Fe}-\mathrm{CN}, \mathrm{CN}-\mathrm{AW}$, and Fe-CN-AW, XRD characterization was performed from $2 \theta$ values $10^{\circ}$ to $80^{\circ}$. The XRD spectra reveal peaks at $27.7^{\circ}$ which are in agreement with the actual XRD peaks of $\mathrm{g}-\mathrm{C}_{3} \mathrm{~N}_{4}$ (JCPDS-871526) [22]. The diffraction peak at $27.7^{\circ}$ indexed to the (002) plane is a characteristic of $\mathrm{g}-\mathrm{C}_{3} \mathrm{~N}_{4}$, showing stacking of aromatic systems between $\mathrm{g}-\mathrm{C}_{3} \mathrm{~N}_{4}$ layers [23]. The XRD pattern of $\mathrm{Fe}-\mathrm{CN}$ exhibited no significant difference from $\mathrm{CN}$ except for a slight shift and gradual decrease in the peak 

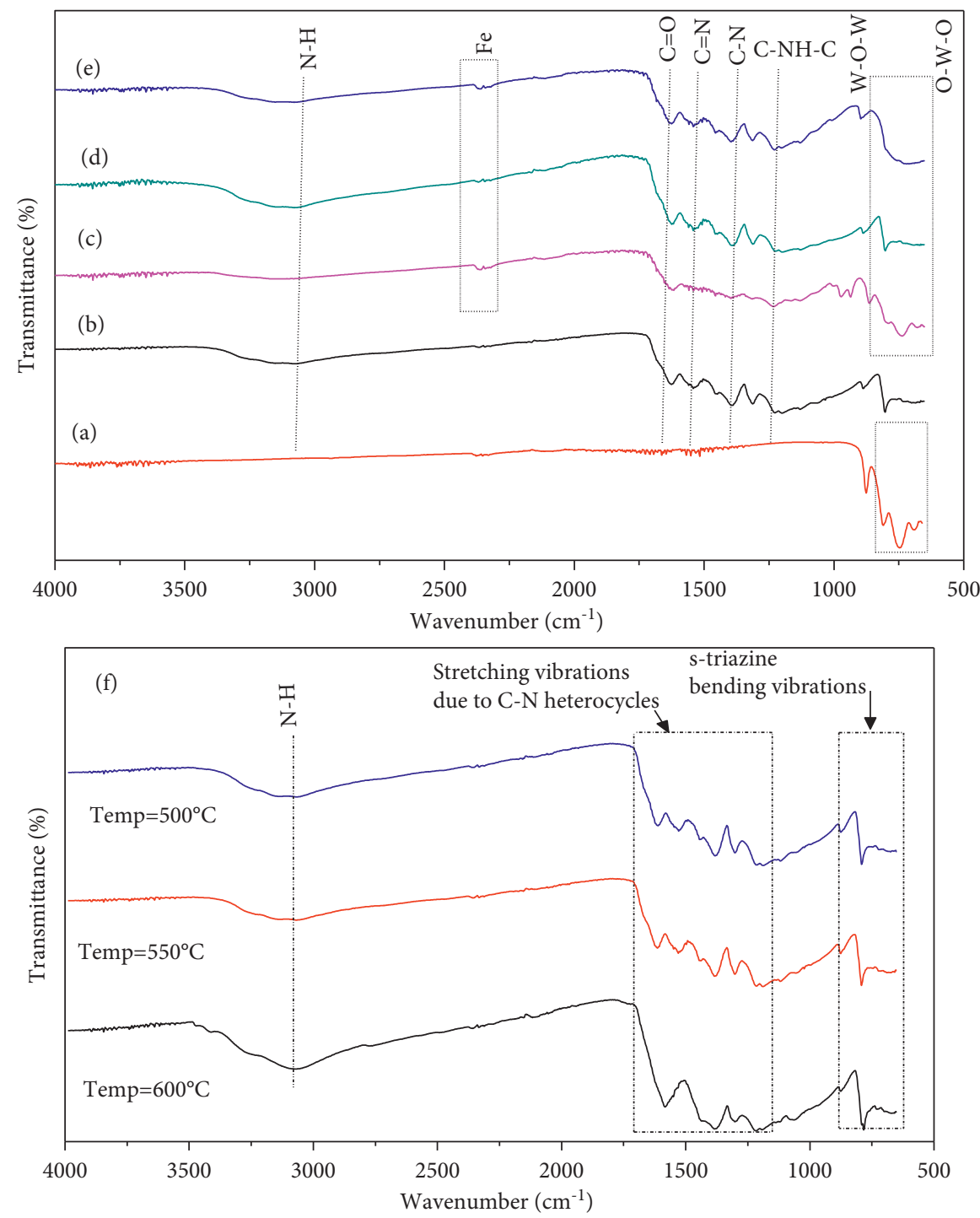

Figure 2: FTIR spectra of (a) AW, (b) g- $\mathrm{C}_{3} \mathrm{~N}_{4}$, (c) Fe-CN, (d) CN-AW, (e) Fe-CN-AW, and (f) g- $\mathrm{C}_{3} \mathrm{~N}_{4}$ at various annealing temperatures.

intensity of the (002) facet in Fe-CN, AW-CN, and Fe-CN$\mathrm{AW}$. The incorporation of an iron dopant in $\mathrm{CN}$ did not change the $\mathrm{g}-\mathrm{C}_{3} \mathrm{~N}_{4}$ crystal structure, as no peak of Fe was identified in the samples [19]. The diffraction peaks of g- $\mathrm{C}_{3} \mathrm{~N}_{4}$ remain intact which shows that the doping of iron does not change the peaks of $g-\mathrm{C}_{3} \mathrm{~N}_{4}$ but the intensity of the peaks in the final composite is reduced, confirming effective insertion of the dopant [24]. The XRD data displayed welldefined diffraction peaks consistent with planes (301), (002), (231), (400), (402), (233), (460), and (462), observed at $2 \theta$ values $28.4^{\circ}, 30.58^{\circ}, 31.67^{\circ}, 32.88^{\circ}, 45.4^{\circ}, 54.9^{\circ}, 56.9$, and $58.04^{\circ}$, respectively, as shown in Figure 3, and are coherent with the corresponding planes of $\mathrm{Ag}_{2} \mathrm{WO}_{4}$ (JCPDS\# 34-0061) [13]. All the characteristic peaks of $\mathrm{g}-\mathrm{C}_{3} \mathrm{~N}_{4}$ and $\mathrm{Ag}_{2} \mathrm{WO}_{4}$ are present in the Fe-doped ternary composite but with lesser intensities than the undoped $\mathrm{CN}-\mathrm{AW}$ and $\mathrm{Fe}-\mathrm{CN}$ composites. However, the strong intensity of diffraction peaks in both the composites suggests the successful synthesis and crystalline nature of composites [25]. There is also a very slight shift of the peak at a diffraction angle of $2 \theta=45.3^{\circ}$, corresponding to a plane (402) towards higher diffraction angles, indicating the insertion of Fe into the host composite lattice. X-ray diffraction is an effective analysis technique to determine the size of nanocrystallites in bulk nanocrystalline materials. The average crystallite size of Fedoped $\mathrm{CN}-\mathrm{AW}$, undoped $\mathrm{CN}-\mathrm{AW}$, and Fe-CN catalysts was assessed using the Debye-Scherrer formula.

$$
D=\frac{K \lambda}{\beta \cos \theta},
$$

where $\mathrm{K}$ is the Scherrer constant (0.94), $\beta$ explains the full width at half maximum (FWHM) of each diffraction peak, $\theta$ is the angle of diffraction, $\lambda$ is the radiation wavelength, and $D$ is the average crystallite size in $\mathrm{nm}$. The average crystallite size of Fe-CN, CN-AW, and Fe-CN-AW was calculated to be 


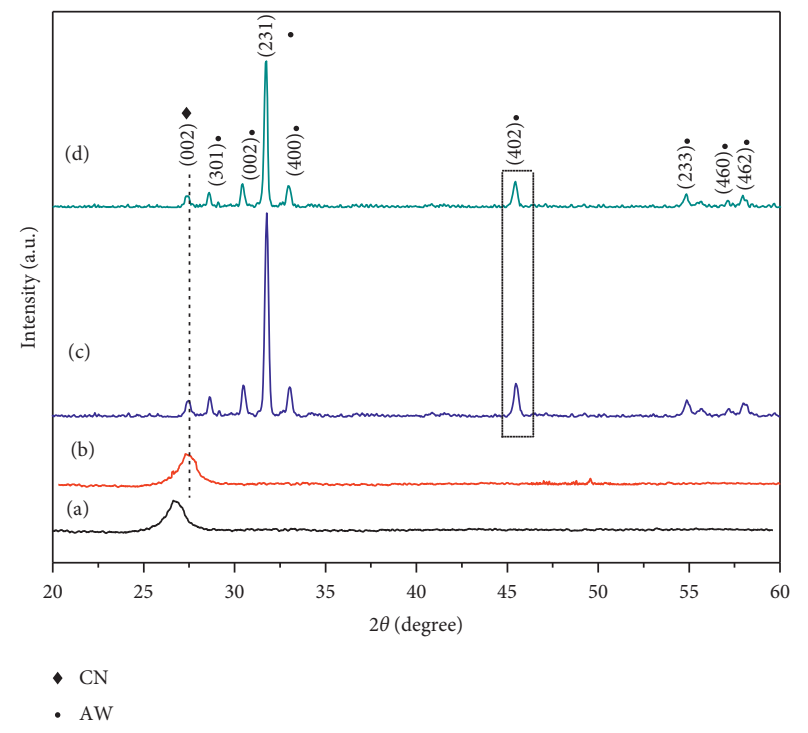

Figure 3: XRD spectra of (a) CN, (b) Fe-CN, (c) CN-AW, and (d) Fe-CN-AW.

$19.78 \mathrm{~nm}, 14.29 \mathrm{~nm}$, and $13.34 \mathrm{~nm}$, respectively. The decreased crystallite size indicates the presence of oxygen vacancies as a result of $\mathrm{Fe}$ doping which hinders the further growth of nanoparticles [26]. The defects caused by $\mathrm{Fe}$ doping reduce recombination chances of charge carriers and enhance photocatalytic activity [27].

3.3. Scanning Electron Microscopy (SEM) Analysis. The SEM analysis was used to study the morphology of Fe-g- $\mathrm{C}_{3} \mathrm{~N}_{4}$, $\mathrm{AW}-\mathrm{CN}$, and $\mathrm{Fe}-\mathrm{CN}-\mathrm{AW}$ nanocomposites at different resolutions. Figures (4(a) and 4(b)) show the morphology of $\mathrm{Fe}-\mathrm{CN}$, revealing uniform and smooth sheets of $\mathrm{g}-\mathrm{C}_{3} \mathrm{~N}_{4}$ and aggregation of particles as an outcome of $\mathrm{Fe}$ doping on g- $\mathrm{C}_{3} \mathrm{~N}_{4}$ sheets. In Figures (4(c) and 4(d)), it can be seen that $\mathrm{Ag}_{2} \mathrm{WO}_{4}$ is dispersed irregularly in the form of small spherical particles on the surface of $\mathrm{g}-\mathrm{C}_{3} \mathrm{~N}_{4}$ sheets. The coupling of $\mathrm{AW}$ and $\mathrm{g}-\mathrm{C}_{3} \mathrm{~N}_{4}$ reveals that the coupling has not affected the morphology of AW spheres. Instead, the g- $\mathrm{C}_{3} \mathrm{~N}_{4}$ aggregates got attached to the surface of silver tungstate. These particles have smooth particle size distribution when present in the form of nonagglomerated particles. The $\mathrm{g}_{-} \mathrm{C}_{3} \mathrm{~N}_{4}$ serves as a support on which $\mathrm{Ag}_{2} \mathrm{WO}_{4}$ particles are embedded. Figures 4(e) and 4(f) signify the coupling between $\mathrm{Fe}-\mathrm{CN}$ and $\mathrm{AW}$ in the ternary composite. These SEM images illustrate those agglomerates of Fe-CN were successfully anchored over AW. In the presence of Fe, the agglomeration and stacking of particles were enhanced as compared to simple AW-CN. Similar results of doping and coupling were also reported in previous studies [28].

3.4. XPS Analysis. The surface chemical composition and chemical binding states of all the photocatalytic samples were analyzed using XPS analysis. The elemental composition of the Fe-CN-AW nanocomposite examined through an XPS survey scan reveals the presence of peaks at $\mathrm{Ag} 3 \mathrm{~d}$ $(368.3 \mathrm{eV}), \mathrm{W}(37.51 \mathrm{eV}), \mathrm{O} 1 \mathrm{~s}(530.2 \mathrm{eV}), \mathrm{C} 1 \mathrm{~s}(284.07 \mathrm{eV})$,
Fe $(710.8 \mathrm{eV})$, and N1s (396.21 eV), as shown in Figure 5(a). The C1s peak position indexed at $285.2 \mathrm{eV}$ in all three samples indicates the presence of adventitious residual carbon and is ascribed to the tertiary carbon $\mathrm{N}=\mathrm{C}-\mathrm{N}_{2}$ in the Fe-g- $\mathrm{C}_{3} \mathrm{~N}_{4}$ lattice. The $\mathrm{N} 1 \mathrm{~s}$ peak present at $396.21 \mathrm{eV}$ is credited to the triazine rings of $g-\mathrm{C}_{3} \mathrm{~N}_{4}$ and the uncondensed terminal amino groups [20]. The $\mathrm{W} 4 f_{7 / 2}$ and $\mathrm{W} 4 f_{5 / 2}$ peaks at $35.44 \mathrm{eV}$ and $37.5 \mathrm{eV}$, respectively, in the $\mathrm{W} 4 \mathrm{f}$ spectrum of $\mathrm{Ag}_{2} \mathrm{WO}_{4}$ are ascribed to $\mathrm{WO}_{4}{ }^{2-}$. The $\mathrm{Ag} 3 \mathrm{~d}$ spectra show two characteristic peaks at $372.1 \mathrm{eV}$ and $368.3 \mathrm{eV}$ which are typically allotted to $\operatorname{Ag~} 3 d_{3 / 2}$ and $\operatorname{Ag} 3 d_{5 / 2}$, respectively. The peaks of Ag3d and W4f XPS spectra moved towards the higher binding energies in the Fe-CN-AW. The Fe $2 \mathrm{p}_{3 / 2}$ at a binding energy of $710.8 \mathrm{eV}$ is ascribed to $\mathrm{Fe}^{3+}$ ions. The binding energy of $710.8 \mathrm{eV}$ lies inside the binding energy range of the $\mathrm{Fe}^{3+}$ valence state $(710-711.8 \mathrm{eV})$. The Fe $2 \mathrm{p}_{1 / 2}$ showed a characteristic peak of $\mathrm{Fe}^{3+}$ at $731.54 \mathrm{eV}$ [19]. The atomic percentage of O1s, N1s, C1s, Ag3p3, Ag3d, W4f, and $\mathrm{Fe} 2 \mathrm{p} 3$ in Fe-CN-AW is $30.3 \%, 22.2 \%, 13.3 \%, 13.2 \%, 10.1 \%$, $7.1 \%$, and $4.3 \%$, respectively, while the atomic percentage of O1s, N1s, C1s, Ag3p3, Ag3d, and W4f in undoped counterpart is $18.9 \%, 19.4 \%, 24.3 \%, 4.6 \%, 16.0 \%, 12.8 \%$, and 8.6 atomic percentages, respectively, as shown in Figure 5(b).

In XPS spectra, the O1s peak found at a binding energy of $528.18 \mathrm{eV}$ is ascribed to the chemisorbed water molecules on the surface of the sample. Furthermore, oxygen functional groups were investigated through O1s spectra, as shown in Figure 5(c). The peaks were found around $530.2 \pm .05 \mathrm{eV}, 531.6 \pm .06$, and $533.5 \pm .04 \mathrm{eV}$ and attributed to the metallic contribution of oxygen ( $\left.\mathrm{O}_{\text {Metallic }}\right)$, carbonyl $(\mathrm{C}=\mathrm{O})$, and carboxyl $(\mathrm{OH})$, respectively $[29,30]$. However, their contributions varied with the addition of dopants. Therefore, Fe-CN showed a total contribution of $\mathrm{O}$ Metallic around $74.85 \%$, while $\mathrm{C}=\mathrm{O}$ and $\mathrm{OH}$ were around 20.93 and 4.23 atomic percentage. The $\mathrm{C}=\mathrm{O}$ was noticed at around $41.32 \%$ and $27.49 \%$ for $\mathrm{CN}-\mathrm{AW}$ and $\mathrm{Fe}-\mathrm{CN}-\mathrm{AW}$, respectively. Moreover, the contribution of $\mathrm{OH}$ was maximum for $\mathrm{Fe}-\mathrm{CN}-\mathrm{AW}$ and was around $22.59 \%$. This increment of $\mathrm{OH}$ is also favorable to enhance the photocatalytic activity of g- $\mathrm{C}_{3} \mathrm{~N}_{4}$-based materials [31].

3.5. Optical Analysis. To further understand the optical properties of the prepared nanocomposites, an evaluation of optical response was carried out by taking UV-Vis spectra and then determining the bandgap energies of nanocomposites $\mathrm{Fe}-\mathrm{CN}, \mathrm{CN}-\mathrm{AW}$, and $\mathrm{Fe}-\mathrm{CN}-\mathrm{AW}$ in the range of 200-800 $\mathrm{nm}$. Using the Tauc plot, the absorption edge of the ternary Fe-CN-AW nanocomposite was found in the visible range $(2.56 \mathrm{eV})$, as shown in Figure 6 . The Fe-CN-AW exhibited a better light absorption range as related to other composites. Fe doping has shown enhancement in photodegradation upon improved prospect of charge carrier production upon light irradiation, eventually increasing photodegradation. The following formula was used to assess the catalyst's bandgap energies [13]:

$$
(\alpha \mathrm{hv})^{2}=B(\mathrm{hv}-\mathrm{Eg})
$$




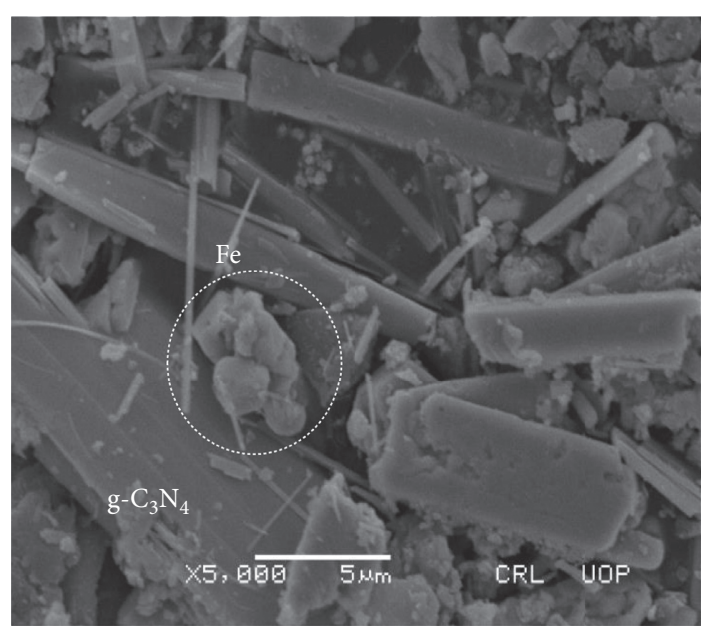

(a)

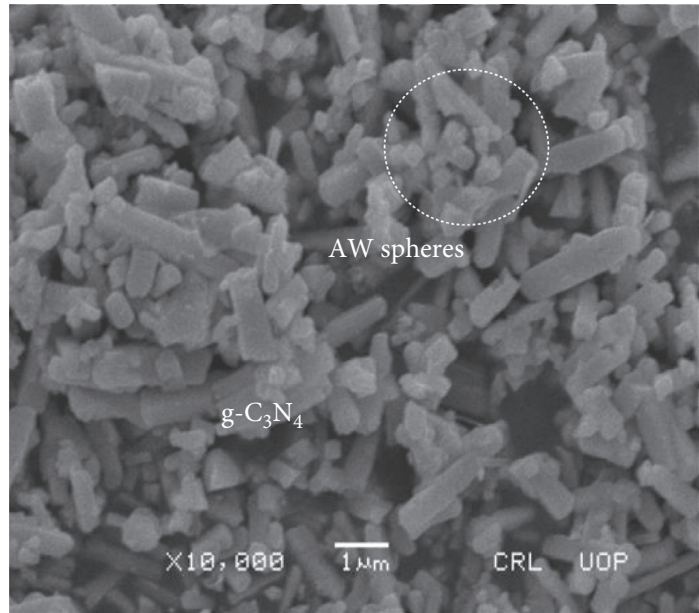

(c)

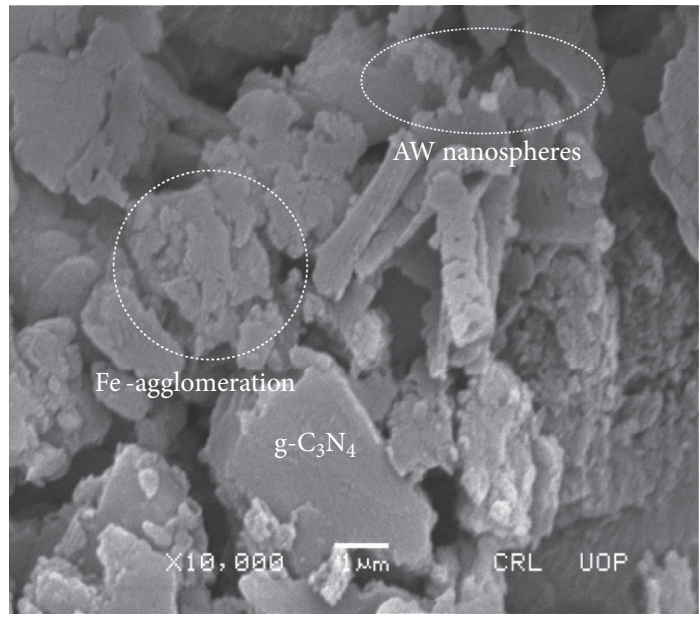

(e)

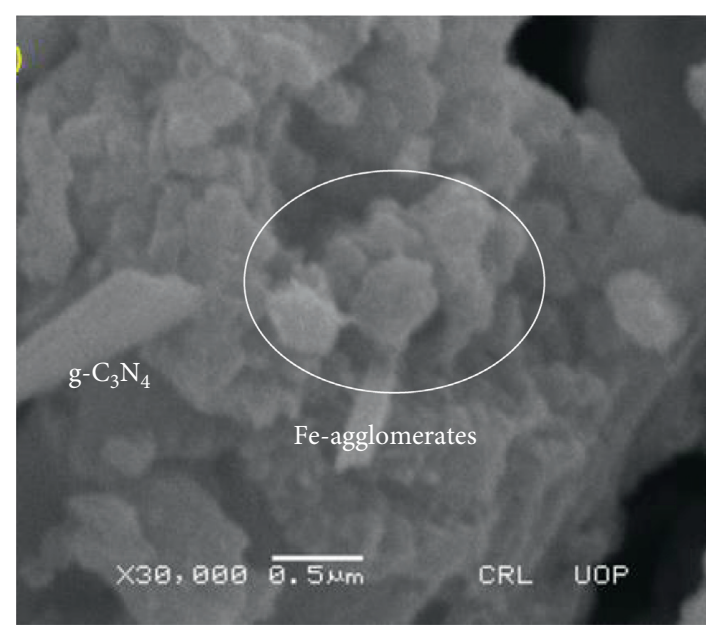

(b)

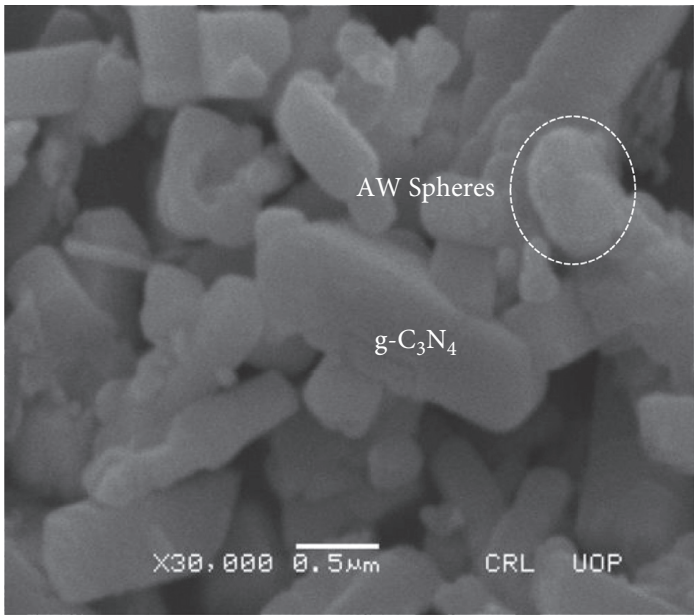

(d)

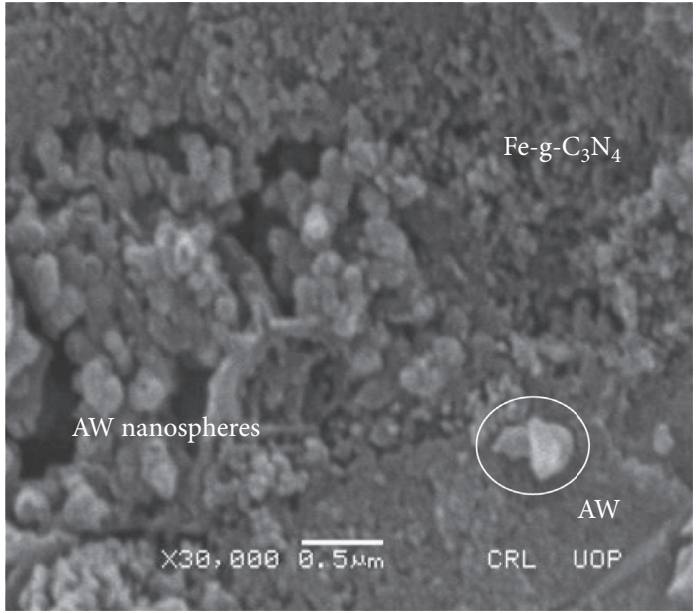

(f)

Figure 4: SEM analysis of (a and b) Fe-CN, (c and d) CN-AW, and (e and f) Fe-CN-AW.

In this equation, energy $(E)=\mathrm{h} \nu$, at $(\alpha \mathrm{h} \nu=0)$, where $(\alpha \mathrm{h} v)^{2}$ is plotted versus energy $(\mathrm{eV})$. At $\mathrm{h} \nu$ value, energy is calculated and then extrapolated to $\alpha=0$. The light frequency, absorption coefficient, and proportionality constant are explained by $(\alpha, \mathrm{B}$, and $\nu)$, respectively. The studies reveal that iron doping has strengthened the light absorption response of the ternary photocatalyst in the visible region. The estimated band gap energies were $2.56 \mathrm{eV}, 2.8 \mathrm{eV}$, and $3.3 \mathrm{eV}$ for $\mathrm{Fe}-\mathrm{CN} / \mathrm{AW}, \mathrm{Fe}-\mathrm{CN}$, and $\mathrm{CN}-\mathrm{AW}$, respectively. The presence of $\mathrm{g}-\mathrm{C}_{3} \mathrm{~N}_{4}$ as support 


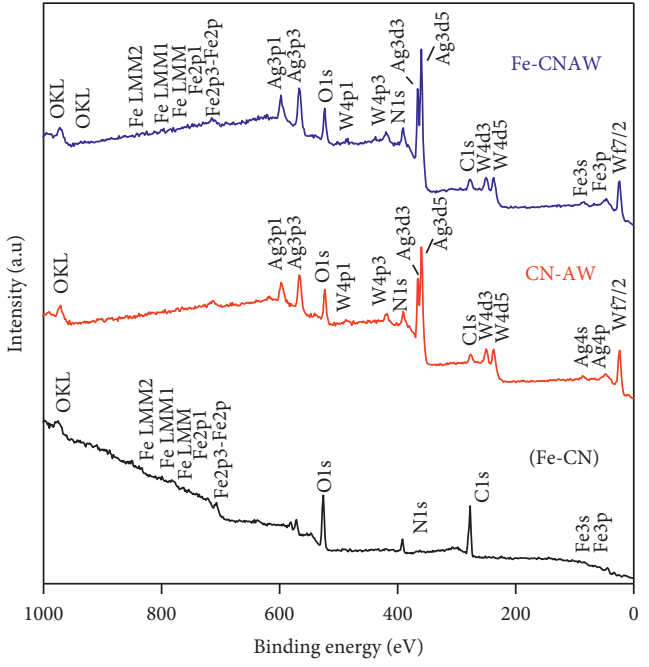

(a)

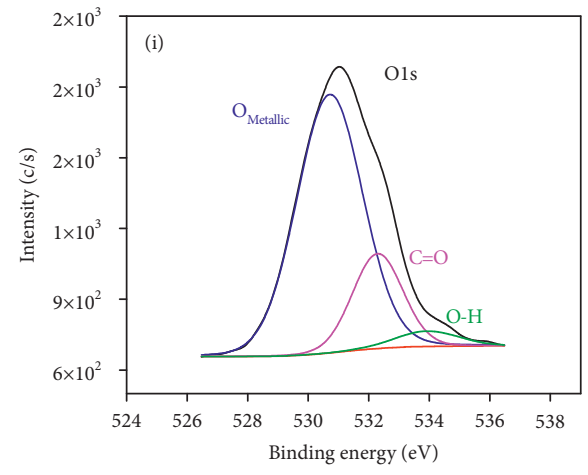

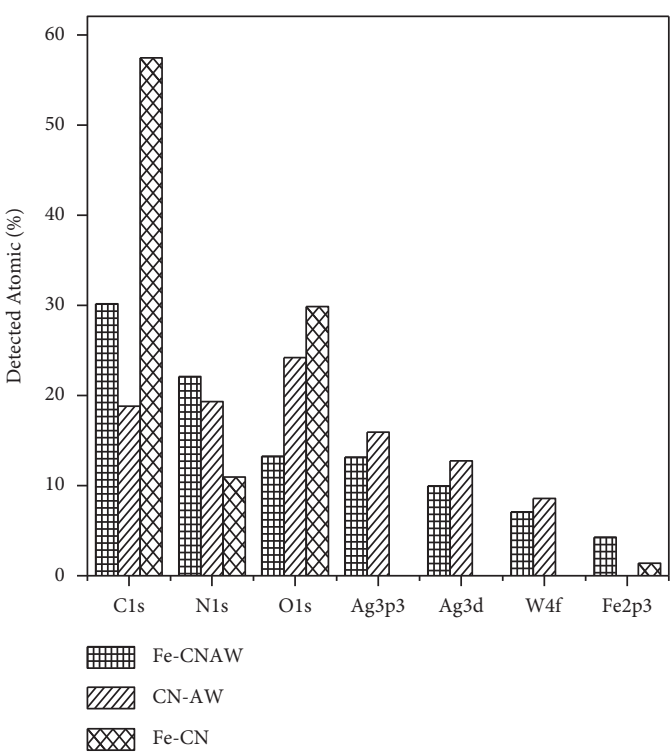

(b)
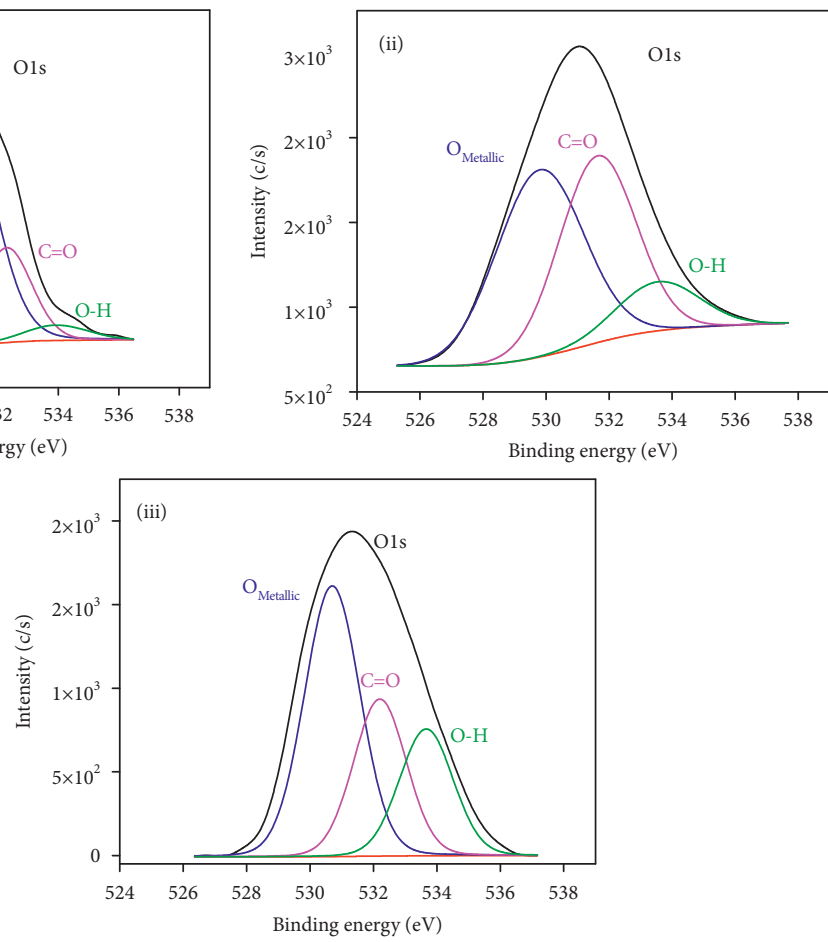

(c)

FIGURE 5: XPS (a) survey spectrum and (b) atomic percentage of various elements in Fe-CN, CN-AW, and Fe-CN-AW; (c) O1s functional groups for (i) $\mathrm{Fe}-\mathrm{CN}$, (ii) $\mathrm{CN}-\mathrm{AW}$, and (iii) $\mathrm{Fe}-\mathrm{CN}-\mathrm{AW}$.

narrowed the bandgap of the ternary composite, suggesting efficient separation of charge carriers [23].

\section{Operating Parameters Affecting the Photocatalytic Process}

The photodegradation process of recalcitrant dyes from the adsorption of molecules of the dye on the photocatalyst's surface to their degradation by reactive radical species is affected by numerous operative parameters. These include $\mathrm{pH}$ of the aqueous solution, initial concentration of dyes (IDC), catalyst dose, and intensity of irradiating light sources. These parameters will be discussed in detail as they directly affect the photodegradation of dyes in wastewaters.

4.1. Effect of $p H$. The photoefficiency of any photocatalytic system is determined by the crucial factor of the $\mathrm{pH}$ of 


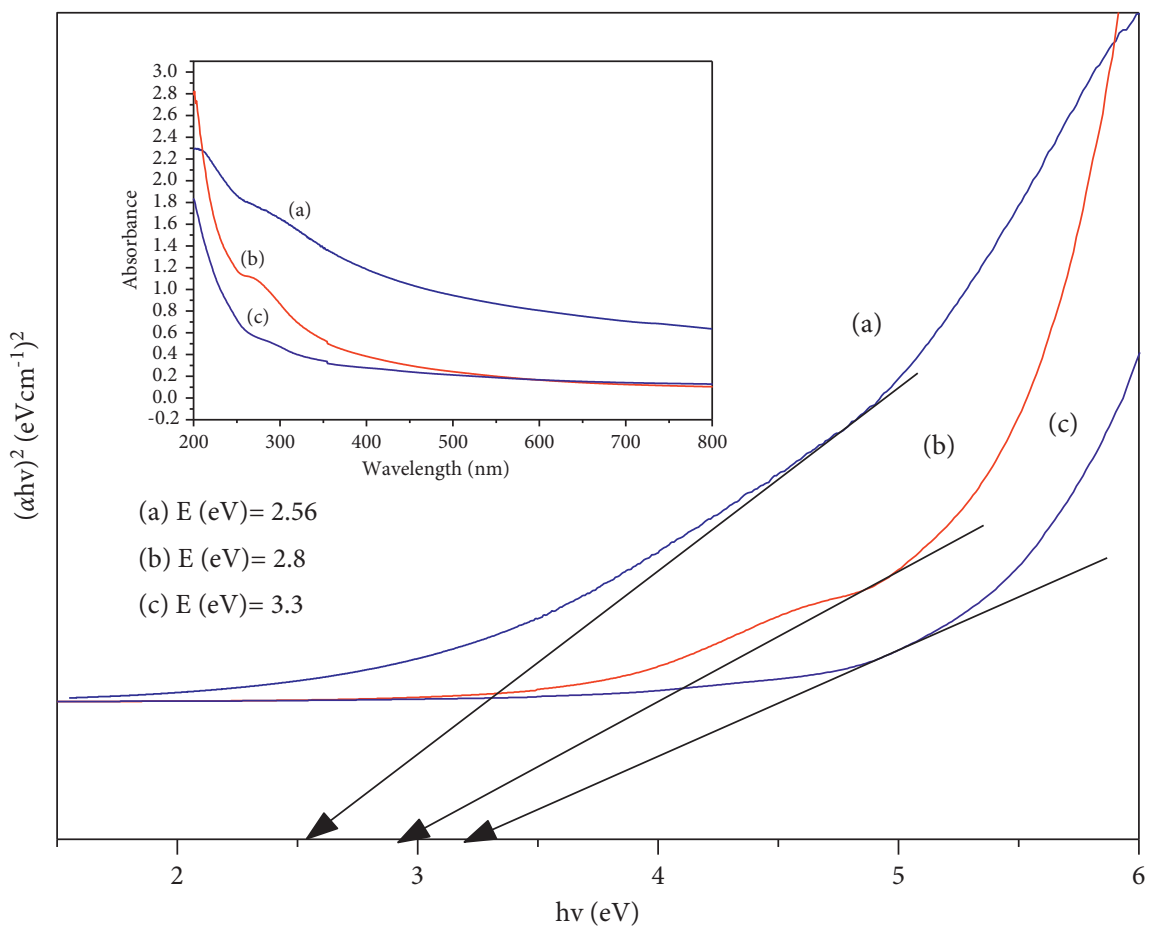

Figure 6: Bandgap energy estimation of (a) Fe-CN/AW, (b) Fe-CN, and (c) CN-AW by the Tauc plot method.

aqueous solutions. The $\mathrm{pH}$ of a solution affects not only the photocatalytic degradation process but also the rate at which the dye decolorizes the positive hole $\left(\mathrm{h}^{+}\right)$species formed at lower $\mathrm{pH}$ values which act as the key oxidation species, while hydroxyl radicals are the key species at higher or neutral $\mathrm{pH}$ values for the degradation process. The surface charge characteristics are determined according to their respective point of zero charges $\left(\mathrm{pH}_{\mathrm{PZC}}\right)$. Acid-base characteristics of photocatalysts significantly impact their degradation efficiencies. At $\mathrm{pH}<\mathrm{pH}_{\mathrm{PZC}}$, the surface of the catalyst is positively charged, and hence, it develops an electrostatic attraction for anions and repulsion for cations. Contrary to this, at $\mathrm{pH}>\mathrm{pH}_{\mathrm{PZC}}$, the surface becomes negatively charged and develops an attraction for cations and repulsion for anions [32]. The $\mathrm{pH}$ effect on $\mathrm{RhB}$ photodegradation was observed by varying $\mathrm{pH}$ values. The remaining factors were kept constant in which the catalyst dose was $50 \mathrm{mg} / 100 \mathrm{~mL}$ for doped and $70 \mathrm{mg} / 100 \mathrm{ml}$ for $\mathrm{Fe}-\mathrm{CN}$ and $\mathrm{CN}-\mathrm{AW}$. IDC was kept at $10 \mathrm{ppm}$ for all composites, and time of irradiation was two hours. Being a cationic dye, upon dissociation in water, $\mathrm{RhB}$ is positively charged. The pHPZC of Fe-CN$\mathrm{AW}$ was determined at a $\mathrm{pH}$ value of 6.2. The catalyst surface is positively charged at $\mathrm{pH}$ values lesser than $\mathrm{pHPZC}$ and, hence, repels positively charged $\mathrm{RhB}$ molecules. Active sites on the surface of the composite become weaker in an acidic medium, producing fewer hydroxyl radicals, leading to a decline in overall degradation, while active sites existing on the surface exhibited improved production of hydroxyl radicals in the basic medium. Henceforth, at $\mathrm{pH}$ values higher than 6.2, the nanocomposite surface becomes negatively charged, attracting positively charged $\mathrm{RhB}$ molecules electrostatically, increasing the adhesion property of pollutant molecules on the composite surface [33]. Therefore, in visible light irradiation, nearly $97 \%$ degradation by ternary $\mathrm{Fe}-\mathrm{CN}-\mathrm{AW}$ in two hours was observed in a basic medium at an optimum $\mathrm{pH}$ of 8 , as shown in Figure 7(a). CN-AW and $\mathrm{Fe}-\mathrm{CN}$ at $\mathrm{pH} 7$ showed nearly $95 \%$ and $90 \%$ degradation, respectively.

4.2. Effect of Catalyst Concentration. The effectiveness of the photocatalyst for the degradation process is determined by its concentration in the dye solution. To comprehend the relation between catalyst dose and $\mathrm{RhB}$ photodegradation, removal of the $10 \mathrm{ppm} \mathrm{RhB}$ solution was studied between the range 10 and $100 \mathrm{mg} / 100 \mathrm{ml}$, while all other parameters such as $\mathrm{pH}=8$ for $\mathrm{Fe}-\mathrm{CN}-\mathrm{AW}$ and $\mathrm{pH}=7$ for $\mathrm{CN}-\mathrm{AW}$ and $\mathrm{Fe}-$ $\mathrm{CN}$, catalyst dosage $50 \mathrm{mg} / 100 \mathrm{ml}$ for doped ternary and $70 \mathrm{mg} / 100 \mathrm{ml}$ for $\mathrm{CN}-\mathrm{AW}$ and $\mathrm{Fe}-\mathrm{CN}$, and irradiation time 120 minutes remained as such. As the photocatalyst dose was augmented from $10 \mathrm{mg}$ to $50 \mathrm{mg}$, an intensification in $\mathrm{RhB}$ degradation was observed, as shown in Figure 7(b). Fe-CNAW showed optimum degradation at $50 \mathrm{mg} / 100 \mathrm{ml}$, whereas $\mathrm{CN}-\mathrm{AW}$ and $\mathrm{Fe}-\mathrm{CN}$ showed maximum degradation at $70 \mathrm{mg} / 100 \mathrm{ml}$. This increased degradation is credited to increased active sites on the surface of the catalyst, which then leads to more production of hydroxyl radicals, which increases the process of degradation. However, above the optimum catalyst loading limit for each catalyst, the percentage degradation starts decreasing. This is because of the interference of light by the suspension. The additional amount of catalyst causes aggregation of catalyst particles 


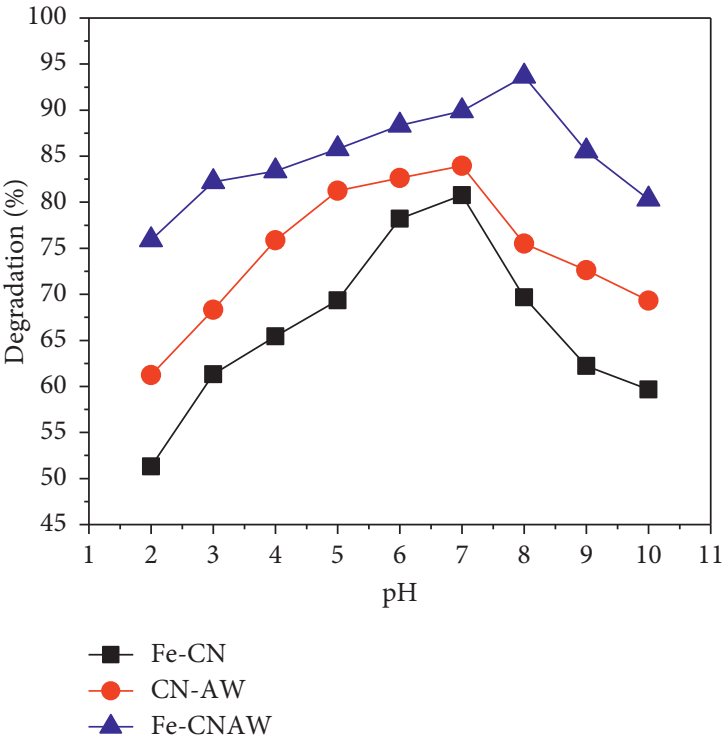

(a)

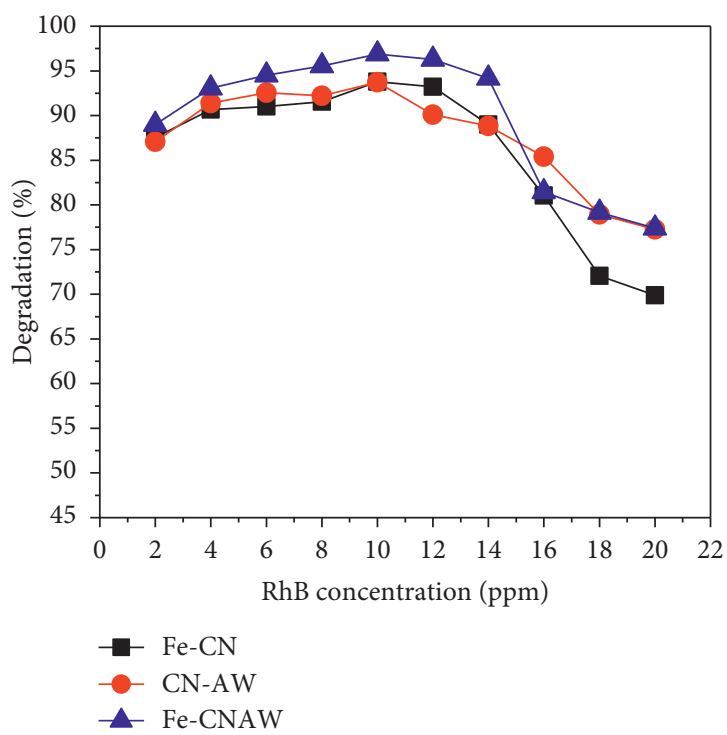

(c)

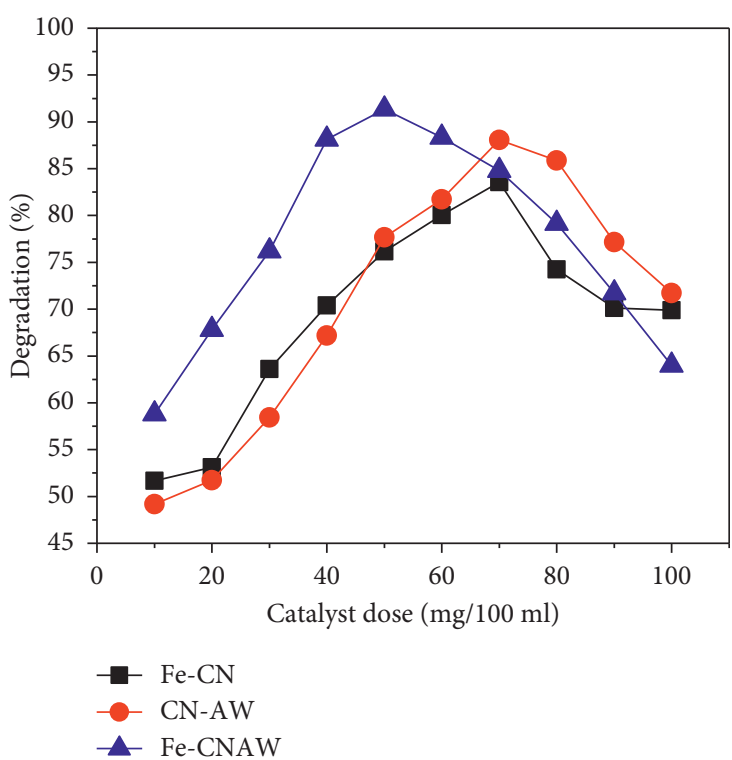

(b)

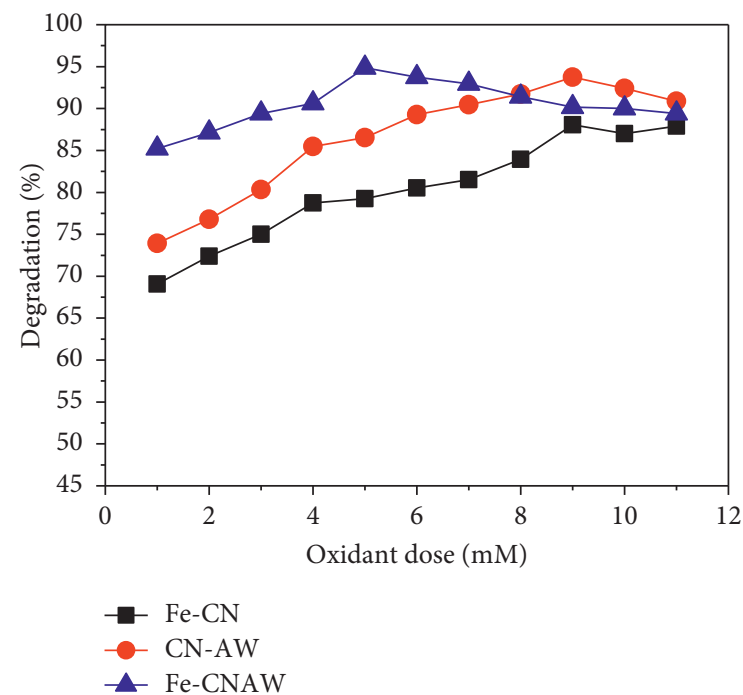

(d)

Figure 7: Optimization of reaction parameters using Fe-CN, CN-AW, and Fe-CN-AW: (a) pH, (b) photocatalyst dose, (c) RhB Initial concentration, and (d) oxidant dose.

and inhibits the light irradiation and subsequent absorption of photons by the catalyst surface, reducing the hydroxyl production and ultimately reducing degradation [34].

4.3. Effect of Initial Dye Concentration. In the degradation process, the total amount of dye adsorbed on the surface of the photocatalyst plays a key role, not the dye molecules present in the bulk solution. The initial dye concentration is a critical factor for determining the complete adsorption capacity of dye molecules. The degradation efficiency starts decreasing as the concentration of dye is increased, while the amount of photocatalyst used is kept constant. The degradation started decreasing after the concentration of dye was increased, as shown in Figure $7(\mathrm{c})$. All samples showed maximum degradation at a concentration of $10 \mathrm{ppm}$, at their optimal values of $\mathrm{pH}$ and catalyst dose. The catalyst Fe-CNAW showed a degradation of $80 \%$ up to $14 \mathrm{ppm}$, after which it started declining. Owing to an increase in the number of dye molecules, more molecules get attached to the photocatalyst surface, resulting in lesser photons reaching the nanocomposite surface [35]. This eventually results in a decline in hydroxyl ion generation and, subsequently, the decolorization process. Previously, reports have revealed 
that the dye degradation rate declined as the dye concentration increased. This is because of the reduction in the path length of photons entering the dye solution as the number of dye molecules increases [33].

4.4. Effect of Oxidant Dose. In the process of photodegradation, oxidants $\left(\mathrm{H}_{2} \mathrm{O}_{2}\right)$ have an important role because they hinder the recombination of $\left(\mathrm{e}^{-}-\mathrm{h}^{+}\right)$pairs by capturing the electron. Furthermore, $\mathrm{OH}$ radicals are generated from the oxidant by the $\mathrm{Ag}^{+2}$ and $\mathrm{Fe}^{2+}$ ion interaction. Rhodamine $\mathrm{B}$ dye is oxidized completely in the presence of an oxidant $\left(\mathrm{H}_{2} \mathrm{O}_{2}\right)$ and a catalyst. In sunlight, the degradation of $\mathrm{RhB}$ dye was enhanced by its adsorption on the catalyst surface due to high tendencies of formation of oxidizing species. By the coupling of semiconductors with g- $\mathrm{C}_{3} \mathrm{~N}_{4}$ photocatalysts, degradation is also enhanced. The adsorption ability of g- $\mathrm{C}_{3} \mathrm{~N}_{4}$ is enhanced in the presence of an oxidant. At $\mathrm{pH}=7$, catalyst dose $=70 \mathrm{mg} / 100 \mathrm{ml}$, and oxidant dose $=9 \mathrm{mM}$, the degradation percentage was $88 \%$ for $\mathrm{Fe} / \mathrm{g}-\mathrm{C}_{3} \mathrm{~N}_{4}$, as represented in Figure 7(d). In the case of the $\mathrm{Ag}_{2} \mathrm{WO}_{4} / \mathrm{g}-\mathrm{C}_{3} \mathrm{~N}_{4}$ composite at $\mathrm{pH}=7$, catalyst concentration $=70 \mathrm{mg}$, and oxidant dose $=9 \mathrm{Mm}$, maximum degradation occurs which is $93 \%$, while in the case of Fe-CN$\mathrm{AW}$ at $\mathrm{pH}=8$, catalyst concentration $=50 \mathrm{mg} / 100 \mathrm{ml}$, and oxidant dose $=5 \mathrm{mM}$, the degradation was equal to $97 \%$.

4.5. Effect of Time. Light energy is a primary source for starting any photocatalytic process because it provides the maximum energy. It is, therefore, necessary to ascertain light irradiation conditions for a substantial impact on the photodegradation process. The trend of $\mathrm{RhB}$ degradation in solar light with time over Fe-CN-AW, CN-AW, and Fe-CN is shown in Figure 8(a), which shows increased degradation with increasing time. The dye solutions having all these catalysts in their optimal doses and other fixed reaction conditions for each catalyst were exposed to sunlight for around 2 hours. The percentage degradation of the treated dye solution was observed by taking a plot of percent degradation versus time. The solution color disappeared exactly after 40 minutes of exposure to light, and degradation was complete after around 120 minutes of light irradiation using the new ternary $\mathrm{Fe}-\mathrm{CN}-\mathrm{AW}$, but intensity decline was slow with $\mathrm{CN}-\mathrm{AW}$ and Fe-CN. The disappearance of solution color signifies that color-imparting chromophores are disintegrating slowly with time. Furthermore, kinetic models were fitted to these data in which first-order kinetic was fitted well.

4.6. Kinetics of Photodegradation Reaction. The first-order kinetic model was applied for RhB photodegradation by the ternary nanocomposite as explained in equation (3).

First-order kinetics:

$$
\text { In } \frac{\mathrm{Co}}{\mathrm{Ct}}=k_{1} t .
$$

Figure 8(b) displays the linear association among $\ln (\mathrm{Co} /$ $\mathrm{Ct}$ ) versus time of reaction; here, $\mathrm{Co}$ and $\mathrm{C}$ explain the initial and final concentrations. This shows that RhB degradation by the ternary $\mathrm{Fe}-\mathrm{CN}-\mathrm{AW}, \mathrm{CN}-\mathrm{AW}$, and $\mathrm{Fe}-\mathrm{CN}$ follows first-order kinetics. The plot of $\ln (\mathrm{Co} / \mathrm{C})$ with time is linear. The linear regression slope is equal to the first-order rate constant $(k)$. The higher $k$ values of Fe-CN-AW than binary $\mathrm{CN}-\mathrm{AW}$ and $\mathrm{Fe}-\mathrm{CN}$ directs that decolorization by Fe-CN$\mathrm{AW}$ under sunlight is more than that by $\mathrm{CN}-\mathrm{AW}$. The $R^{2}$ values for first-order reaction for Fe-CN-AW, CN-AW, and Fe-CN-AW suggest that ternary hybrids follow first-order reaction efficiently and doping has accelerated degradation in the presence of sunlight. This explains that Fe-CN-AW exhibits more photoefficiency than other composites. An assessment of correlation coefficients for first-order kinetics is shown in Table 1.

\section{Statistical Analysis}

The photocatalytic degradation procedure was mostly determined by the widely employed technique RSM which studies the optimization of parameters. In RSM, mathematics is combined with statistics for empirical representation. The purpose of RSM is to optimize photocatalyst response for different parameters to degrade $\mathrm{RhB}$ degradation. It works efficiently for experimental studies. It also reduced the noise and expenses of analytical procedures. It minimizes the expenditure of expensive analysis techniques. In the present work, the Fe-CN-AW ternary composite was synthesised by a hydrothermal technique and utilized for $\mathrm{RhB}$ degradation. For example, various parameters such as catalyst dose, $\mathrm{pH}$, oxidant dose, and time were optimized by RSM, and absorbance was noted by using a UV-Vis spectrophotometer.

In RSM, for statistical analysis of dye degradation, a central composite design (CCD) was used. According to the CCD, 30 experiments were conducted for the study of the photo-Fenton procedure. Each experimental trial has specific coRhBinations of four elements, e.g., $\mathrm{pH}$, oxidant dose, catalyst dose, and irradiation time. After each experimental trial, percent degradation was calculated and put into a table. Some experimental trials have the same coordination of factors to have the idea of experimental error. Analysis of variance (ANOVA) was used to evaluate the effectiveness of the regression model, as shown in Table 2.

The photodegradation of $\mathrm{RhB}$ was optimized using the central composite design (CCD) of the response surface methodology. Among all RSM designs, the CCD method shows high predictability of responses and is the most efficient method for optimizing several variables. The CCD is used for determining the relationship among independent variables and their responses [36].

Based on the results from batch studies, four effective parameters for the degradation of $\mathrm{RhB}$ by $\mathrm{Fe}-\mathrm{CN}-\mathrm{AW}$ and their possible interactions were identified using RSM. The pH (2-9), photocatalyst dose (10-80 mg), oxidant dose $(2-12 \mathrm{mM})$, and time $(20-180)$ in minutes were designated as independent variables, and the effect of their interactions was determined using the CCD. The statistical software Design Expert 7 was used for the optimization of parameters. A total of 30 experiments were obtained randomly for 


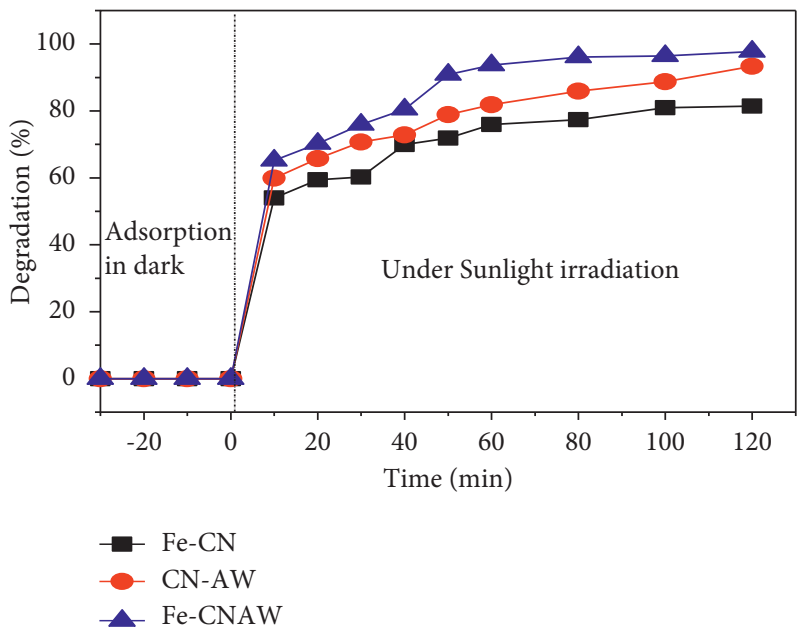

(a)

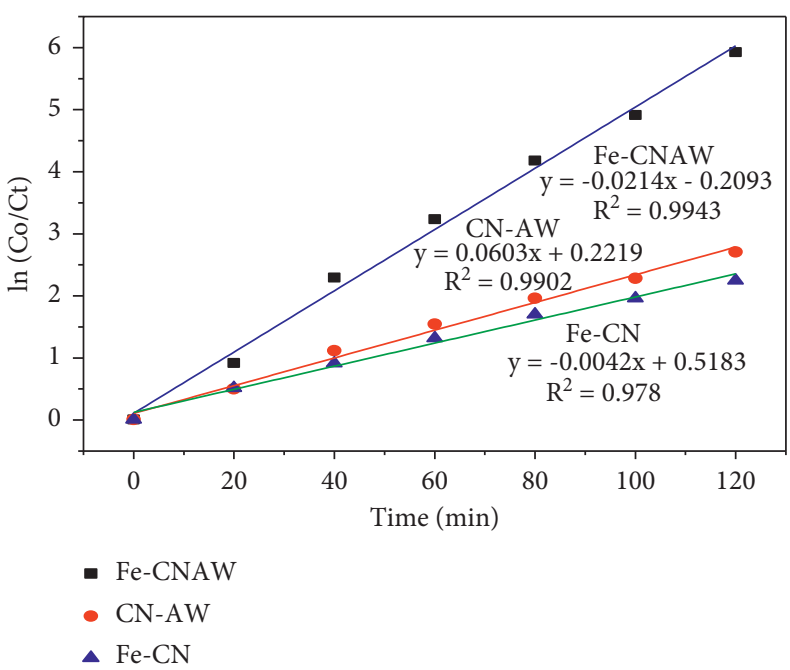

(b)

Figure 8: (a) RhB degradation by all catalysts as a function of time under sunlight and (b) first-order kinetic model fitting.

TABLE 1: Correlation coefficients $\left(R^{2}\right)$ and kinetic parameters for $\mathrm{RhB}(\mathrm{Co}=10 \mathrm{ppm})$ degradation.

\begin{tabular}{|c|c|c|c|c|c|}
\hline \multirow{2}{*}{ Nanocomposites } & \multicolumn{3}{|c|}{ Optimized reaction conditions } & \multicolumn{2}{|c|}{ First-order kinetics } \\
\hline & $\mathrm{pH}$ & Catalyst load (mg/ml) & IDC (ppm) & $k 1\left(\min ^{1}\right)$ & $R^{2}$ \\
\hline Fe-CN-AW & 8 & 50 & 10 & 0.0214 & 0.9943 \\
\hline CN-AW & 7 & 70 & 10 & 0.0603 & 0.9902 \\
\hline $\mathrm{Fe}-\mathrm{CN}$ & 7 & 70 & 10 & 0.004 & 0.978 \\
\hline
\end{tabular}

studying the optimized parameters and for maximizing RhB photodegradation. The ANOVA (analysis of variance) was used to analyze the effect of all independent variables on the degradation of dye. The response variable (\% degradation) was fitted with the quadratic model for corelating with the experimental variables. The predicted and experimental values are tabulated in Table 2 . To understand the association of three variables, a second-order polynomial equation was employed. The quadratic regression model for the degradation of $\mathrm{MB}$ is represented by equation (3).

$$
\begin{aligned}
y= & \beta_{0}+\beta_{1} X_{1}+\beta_{2} X_{2}+\beta_{3} X_{3}+\beta_{4} X_{4}+\beta_{12} X_{1} X_{2}+\beta_{13} X_{1} \beta X_{3} \\
& +\beta_{14} X_{1} \beta X_{4}+\beta_{11} X_{1}^{2}+\beta_{22} X_{2}^{2}+\beta_{33} X_{3}^{2}+\beta_{44} X_{4}^{2}, \\
Y= & +88.67+7.3 * A+7.1 * B-2.83 * C+6.9 * D+0.38 * A * B+1.50 * A * C \\
& +1.38 * A * D+0.000 * B * C-3.12 * B * D+0.50 * C * D \\
& -6.65 * A^{2}-1.65 * B^{2}-3.77 C^{2}-2.27 * D^{2} .
\end{aligned}
$$

The $3 \mathrm{D}$ response was studied for the interactive relationship between the four parameters on dye degradation. For the determination of maximum degradation, 3D surfaces were plotted and taken into consideration. From this, interaction among two independent variables was established, keeping the other variables constant. For the degradation of dye, $\mathrm{pH}$ is an efficient parameter. The maximum degradation of $\mathrm{RhB}$ dye over Fe-CN-AW was observed at $\mathrm{pH}=8$ and catalyst dosage $=50 \mathrm{mg}$ in $100 \mathrm{ml}$ of dye solution. Figure 9(a) reveals an enhancement in degradation efficiency by increasing the Fe-CN-AW dose up to an optimal value at $\mathrm{pH}$ value $=8$. These interactions show the effect of $\mathrm{pH}$ on the surface charge properties of the Fe-CN-AW ternary composite, consequently affecting the adsorption of RhB molecules on the surface of the catalyst. Meanwhile, the reaction amongst holes $\left(\mathrm{h}^{+}\right)$, present on the surface of Fe-CN-AW, and hydroxide ions, leads to the generation of $\mathrm{OH}$ radicals, being the chief reactive species to initiate degradation. Therefore, a basic environment supports more hydroxyl radical production and reduction in recombination between $\mathrm{e}-/ h+$ pairs. Moreover, the electrostatic interactions between negatively charged $\mathrm{Fe}-\mathrm{CN}-\mathrm{AW}$ and positively charged $\mathrm{RhB}$ dye molecules increase in the basic medium. In an acidic medium or at higher $\mathrm{pH}$ values above 9, the repulsion 
TABle 2: ANOVA table for degradation of RhB by Fe-g- $\mathrm{C}_{3} \mathrm{~N}_{4}-\mathrm{Ag}_{2} \mathrm{WO}_{4}$

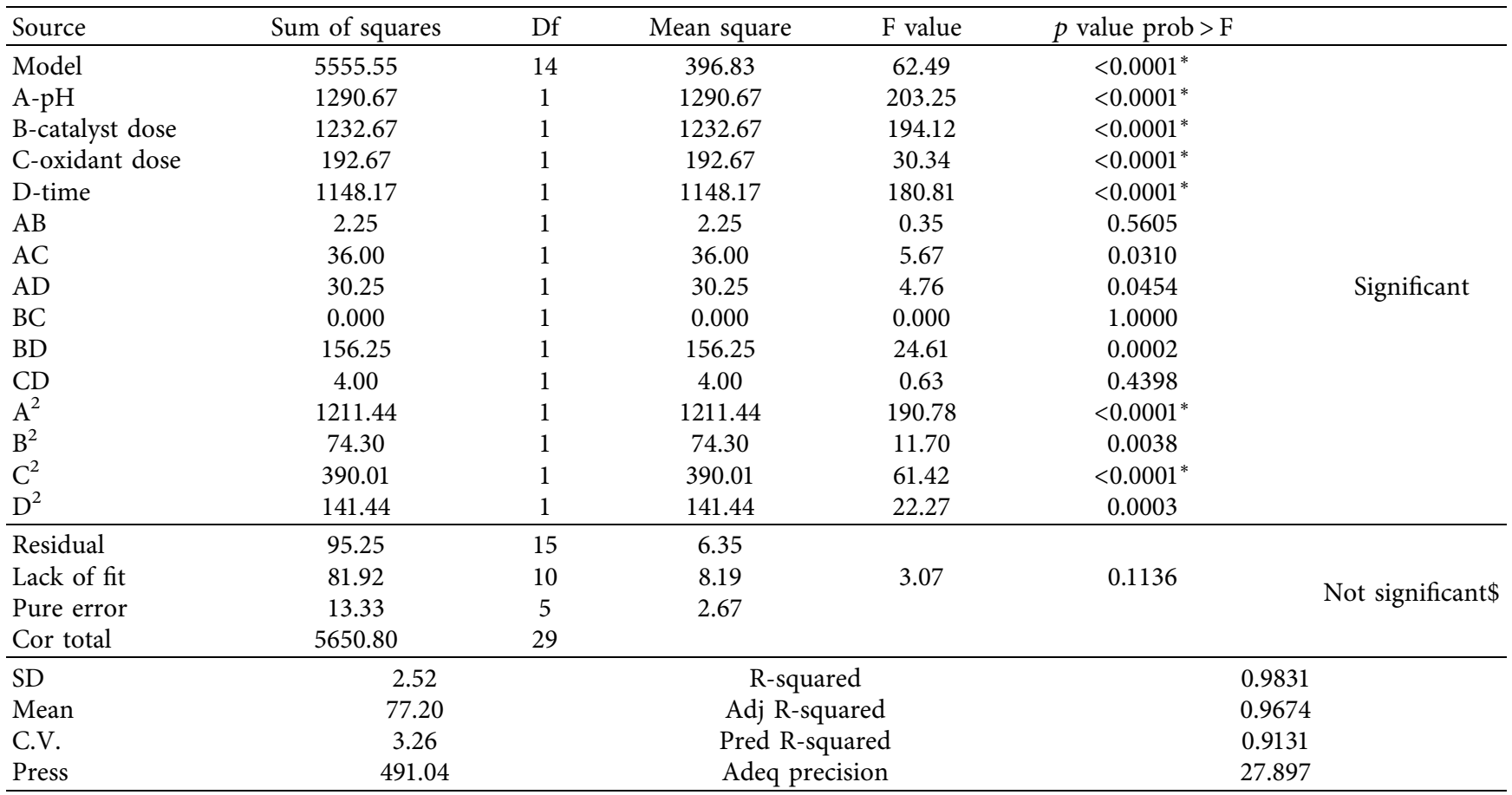

* Significant model terms. \$Nonsignificant lack of fit is good. We want the model to fit.

between hydroxide ions and the negatively charged composite causes agglomeration and hinders the formation of hydroxyl radicals, leading to a decrease in degradation efficiency [37]. At higher catalyst dose values above optimum value, the agglomeration of $\mathrm{Fe}-\mathrm{CN}-\mathrm{AW}$ particles leads to reduced surface area for irradiation under sunlight, reducing dye removal efficiency.

Figure 9(b) shows contours and 3D plots of the interaction between oxidant dose and $\mathrm{pH}$. Maximum degradation was observed at an oxidant dose of $5 \mathrm{mM}$ at an optimum $\mathrm{pH}$ value of 8. Oxidant $\left(\mathrm{H}_{2} \mathrm{O}_{2}\right)$ inhibits the recombination of $\mathrm{e}^{-}$ and $\mathrm{h}^{+}$pairs. The response was observed to increase by changing the $\mathrm{pH}$ of the solution between values of 6 and 8 . An increase in oxidant dose has led to a decline in degradation due to the recombination of hydroxyl radicals and decline in the absorption of light due to saturation. Henceforth, at an oxidant dosage of $5 \mathrm{mM}$ and $\mathrm{pH}=8$, maximum degradation was observed. Figure 9(c)) shows the relationship between $\mathrm{pH}$ and time by a $3 \mathrm{D}$ contour plot. Degradation increased as the $\mathrm{pH}$ and time were increased until an optimum condition was achieved. This shows that $\mathrm{pH}$ and time are crucial factors for enhancing the overall catalytic activity. The increase in $\mathrm{RhB}$ degradation by $\mathrm{Fe}-$ $\mathrm{CN}-\mathrm{AW}$ was studied until the optimum values. After that, it begins to decrease. The reason behind it was as time increased, the reaction between the catalyst and dye molecules enhanced, which enhanced the degradation. Figure 9(d) shows the relationship between catalyst dose and oxidant dose. The 3D plots show that increasing the Fe-CN-AW dose from $10 \mathrm{mg} / 100 \mathrm{ml}$ improved the degradation greatly to an optimum dose of $50 \mathrm{mg} / 100 \mathrm{ml}$ and an oxidant dose of $5 \mathrm{mM}$, where it showed a maximum degradation. As the amount of catalyst is increased, the number of active sites for the dye molecules to get adsorbed also increases; eventually, degradation is increased. However, a further increase in catalyst dose resulted in slower degradation rate due to the agglomeration of particles, thus obstructing the light penetration in the solution. The presence of an oxidant prevents $\mathrm{e}^{-} / \mathrm{h}^{+}$pairs from recombining. The improved $\mathrm{RhB}$ degradation is attributed to the possible reaction of $\mathrm{Fe}$ ions with oxidant species producing molecular oxygen species and more hydroxyl radicals leading to enhanced photocatalytic degradation [28].

From Figure 9(e), the interaction between $\mathrm{Fe}-\mathrm{CN}-\mathrm{AW}$ dosage and time is evident. It was seen that as the catalyst dose and time increased up to the optimized values, degradation also enhanced, showing a positive effect of catalyst amount and time. As the time duration of sunlight irradiation was increased from 1 hour to 2 hours and catalyst dose up to $50 \mathrm{mg} / 100 \mathrm{ml}$, the degradation increased. A further increase in dose above $50 \mathrm{mg}$ at 2 hours of irradiation shows a steady decline in degradation due to the blocking of the active sites.

\section{Scavenger Study and the Proposed Mechanism}

To investigate the role of key scavengers for $\mathrm{RhB}$ degradation by ternary Fe-CN-AW under sunlight, the following conditions of experimental reaction were used: $\mathrm{pH}=8$, catalyst loading $=50 \mathrm{mg} / 100 \mathrm{ml}, \quad$ IDC $=10 \mathrm{ppm}, \quad \mathrm{H}_{2} \mathrm{O}_{2}$ concentration $=5 \mathrm{mM}$, and irradiation time 120 minutes. DMSO, EDTA, $\mathrm{K}_{2} \mathrm{Cr}_{2} \mathrm{O}_{7}$, and ascorbic acid were employed as scavenging agents for hydroxyl radicals, holes, electrons, and 


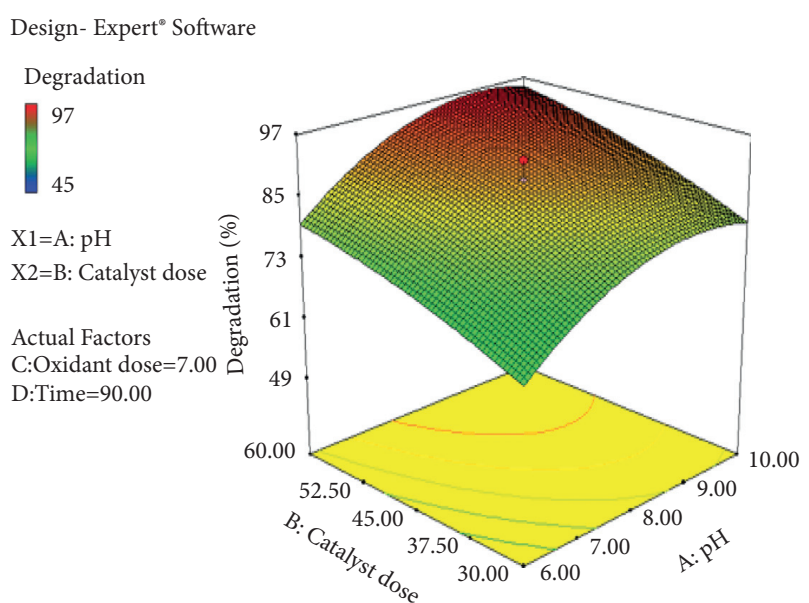

(a)

Design- Expert ${ }^{\circ}$ Software Degradation

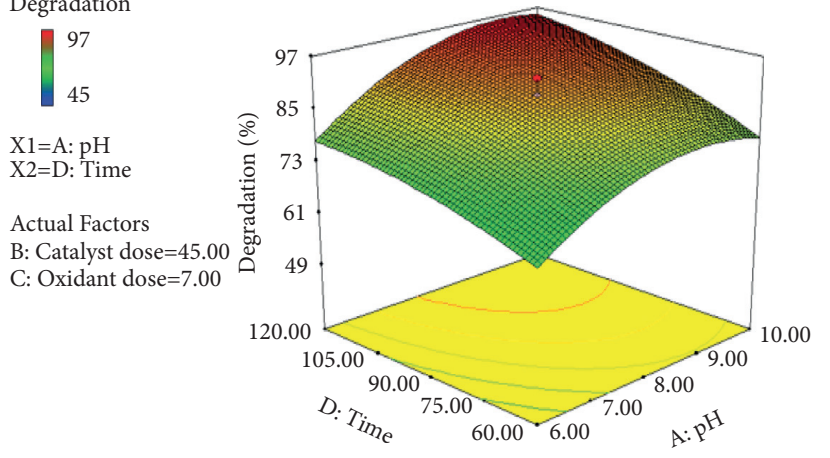

(c)

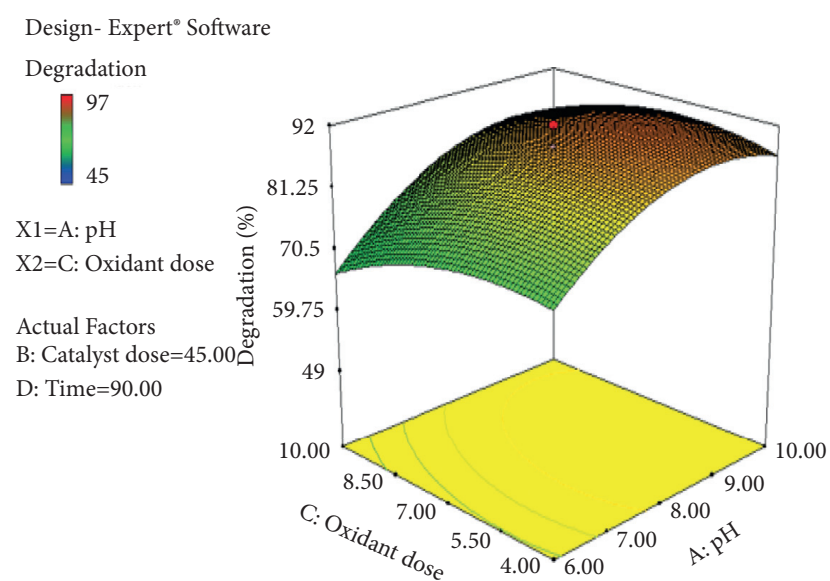

(b)

Design- Expert ${ }^{\oplus}$ Software

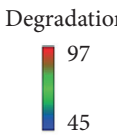

$\mathrm{X} 1=\mathrm{B}$ : Catalyst dose $\mathrm{X} 2=\mathrm{C}$ : Oxidant dose

Actual Factors A: $\mathrm{pH}=8.00$

D: Time $=90.00$

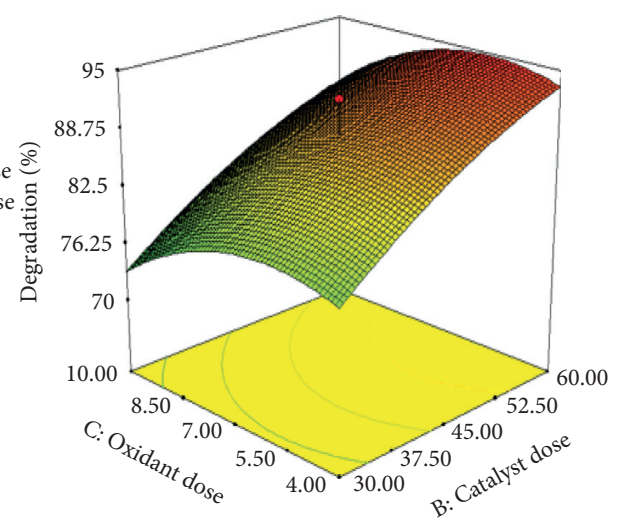

(d)

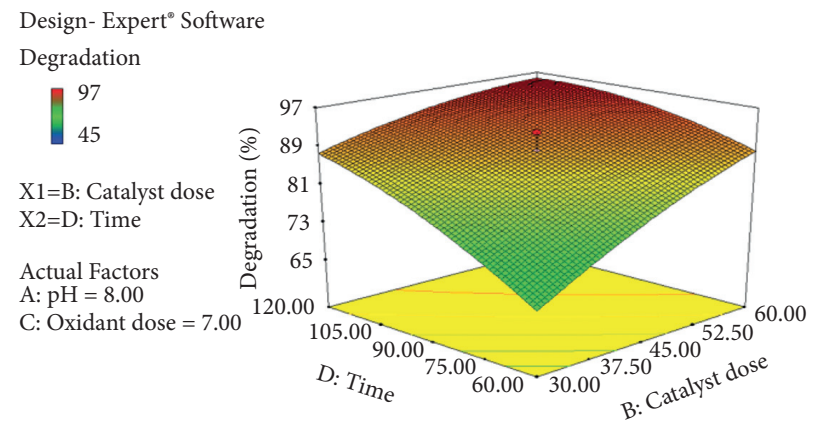

(e)

FiguRE 9: Response surface methodology showing the interaction of various reaction parameters. Interaction between (a) catalyst dose and $\mathrm{pH}$, (b) oxidant dose and $\mathrm{pH},(\mathrm{c})$ time and $\mathrm{pH},(\mathrm{d})$ catalyst dose and oxidant dose, and (e) time and catalyst dosage.

superoxide radical $\left(\mathrm{O}_{2}{ }^{-2}\right)$, respectively. The concentration of all these scavengers was kept at $5 \mathrm{mM}$ during the experiments executed under sunlight. The active radical was immediately scavenged by the appropriate scavenger while the rest of the radicals carried out the dye degradation. The evaluation of the activities of the investigated scavenging agents is shown in Figure 10(a). The results indicate that the maximum reduction in catalytic activity was observed by the addition of EDTA, ascorbic acid, and then, DMSO and the least by the addition of $\mathrm{K}_{2} \mathrm{Cr}_{2} \mathrm{O}_{7}$. Figure 10 (a) shows the decrease in degradation from $97 \%$ to $32 \%, 47 \%, 54 \%$, and $89 \%$, respectively. Accordingly, $\mathrm{h}^{+}, \bullet \mathrm{O}^{2-}$, and ${ }^{\circ} \mathrm{OH}$ are produced and involved in the photocatalytic reaction, while electrons play a minor role. On this basis, the proposed mechanism of Fe-CN-AW is as suggested in Figure 11.

Under visible light irradiation, both the $\mathrm{Fe}-\mathrm{CN}$ and $\mathrm{Ag}_{2} \mathrm{WO}_{4}$ can be excited and produce light-induced es ${ }^{-}$and $\mathrm{h}^{+}$. Photoinduced $\mathrm{es}^{-}$in the conduction band (CB) of silver tungstate is easily transferred to the $\mathrm{Fe}-\mathrm{CN}$ valence band (VB). This is probably because of electrostatic interactions 


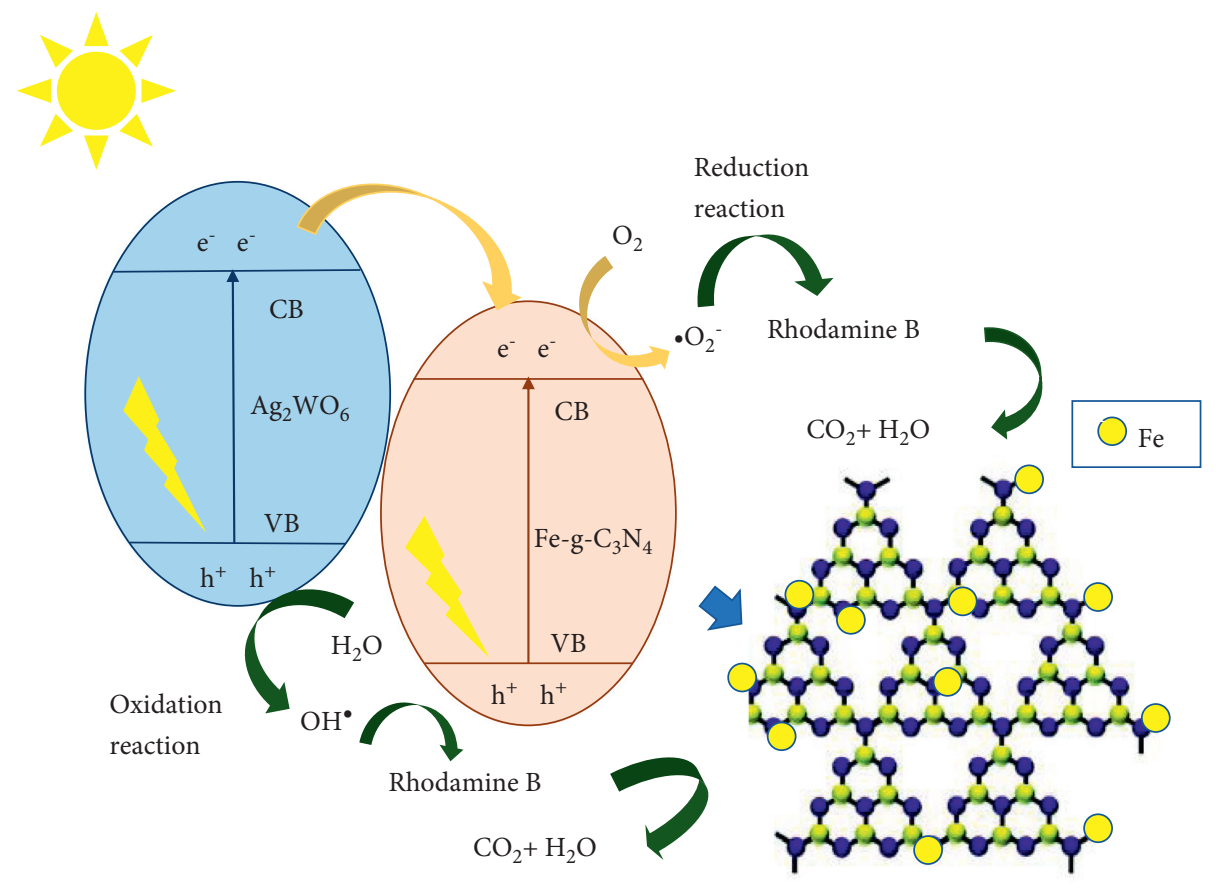

FIgURe 10: Proposed mechanism of rhodamine B dye degradation using ternary Fe-CN-AW.

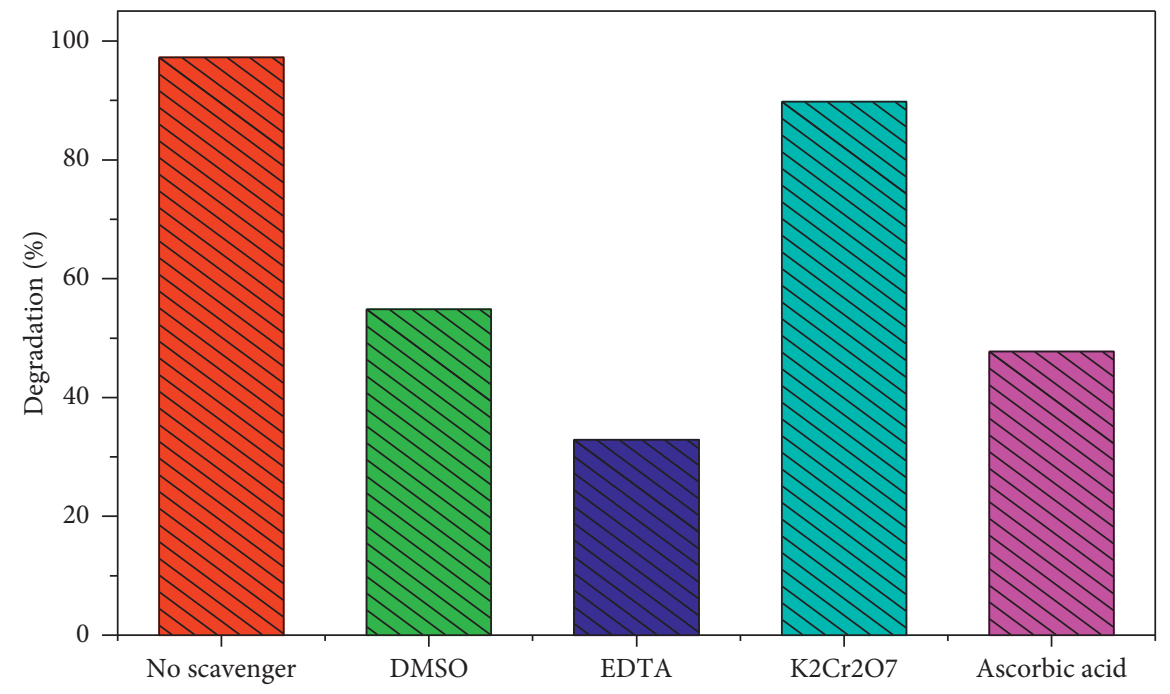

(a)

Figure 11: Continued. 

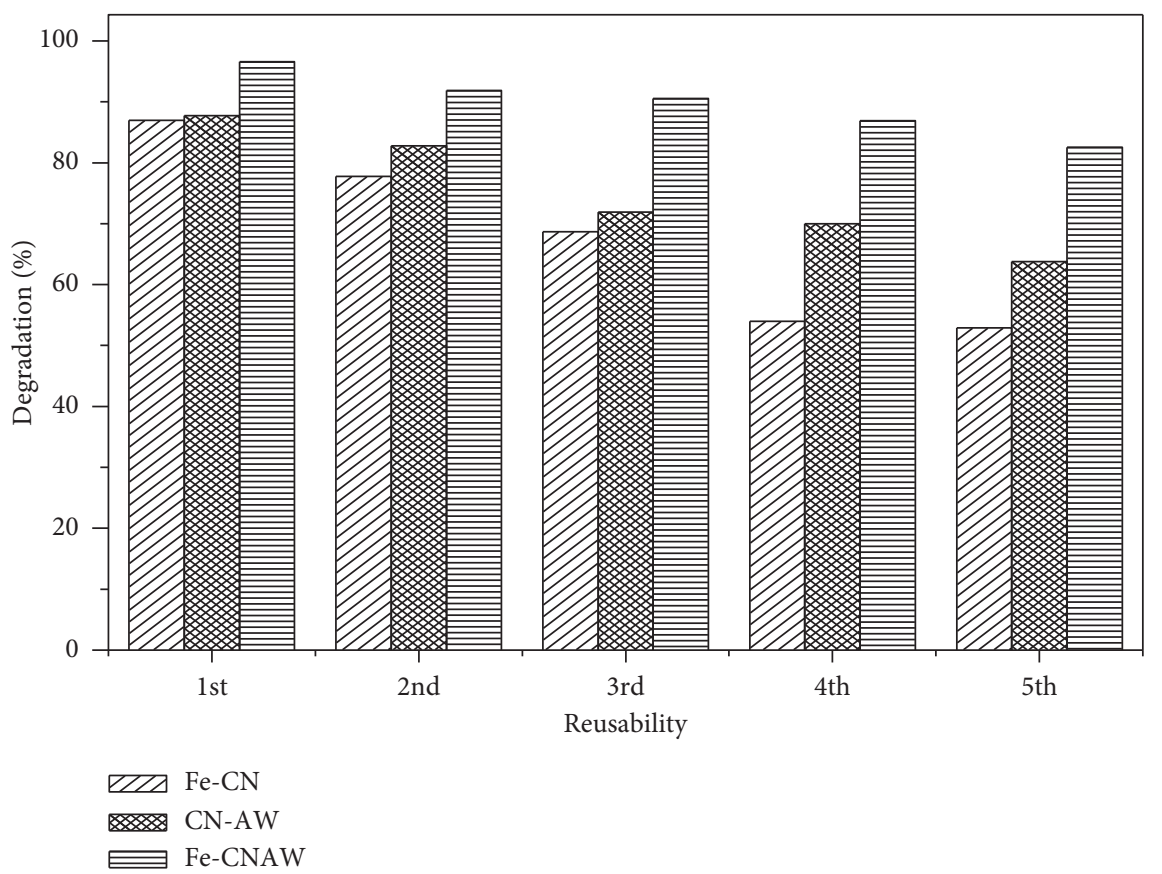

(b)

Figure 11: (a) Experiment on the role of several radical scavengers and (b) reusability experiment by Fe-CN, CN-AW, and Fe-CN-AW nanocomposites.

TABLE 3: Comparison of the degradation performance of metal/nonmetal doped $g-\mathrm{C}_{3} \mathrm{~N}_{4}$-based ternary photocatalysts.

\begin{tabular}{|c|c|c|c|c|c|c|c|}
\hline $\begin{array}{l}\text { Sr. } \\
\text { no. }\end{array}$ & Photocatalysts & Fabrication methods & $\begin{array}{c}\text { Target } \\
\text { pollutants }\end{array}$ & $\begin{array}{l}\text { Light } \\
\text { source }\end{array}$ & $\begin{array}{l}\text { Degradation time } \\
(\mathrm{min})\end{array}$ & $\begin{array}{l}\text { Photocatalytic } \\
\text { activity }(\%)\end{array}$ & References \\
\hline 1. & $\mathrm{P}-\mathrm{g}-\mathrm{C}_{3} \mathrm{~N}_{4}-\mathrm{ag}_{2} \mathrm{WO}_{4}$ & $\begin{array}{l}\text { Thermal polymerization } \\
\text { method }\end{array}$ & Indomethacin & $\begin{array}{l}\text { Visible } \\
\text { light }\end{array}$ & 60 & 91 & {$[11]$} \\
\hline 2. & $\mathrm{Ag}-\mathrm{g}-\mathrm{C}_{3} \mathrm{n}_{4} / \mathrm{FeWO}_{4}$ & Hydrothermal & Rhodamine B & $\begin{array}{l}\text { Visible } \\
\text { light }\end{array}$ & 120 & 98 & {$[28]$} \\
\hline 3. & $\begin{array}{c}\mathrm{P}-\mathrm{S}-\mathrm{g}-\mathrm{C}_{3} \mathrm{~N}_{4} / \\
\mathrm{Ag}_{2} \mathrm{CO}_{3}\end{array}$ & $\begin{array}{l}\text { Ion-exchange deposition } \\
\text { method }\end{array}$ & $\begin{array}{c}2,4- \\
\text { Dinitrophenol }\end{array}$ & $\begin{array}{l}\text { Visible } \\
\text { light }\end{array}$ & 360 & 99 & [38] \\
\hline 4. & $\mathrm{O}-\mathrm{g}-\mathrm{C}_{3} \mathrm{~N}_{4} / \mathrm{ZnIn}_{2} \mathrm{~S}_{4}$ & Hydrothermal method & $\begin{array}{c}2,4- \\
\text { Dinitrophenol }\end{array}$ & $\begin{array}{l}\text { Visible } \\
\text { light }\end{array}$ & 180 & 92 & {$[39]$} \\
\hline 5. & $\begin{array}{c}\mathrm{P}-\mathrm{S}-\mathrm{g}-\mathrm{C}_{3} \mathrm{~N}_{4} / \\
\mathrm{Ag}_{2} \mathrm{VO}_{3}\end{array}$ & $\begin{array}{l}\text { Ion-exchange deposition } \\
\text { method }\end{array}$ & Phenol & $\begin{array}{l}\text { Visible } \\
\text { light }\end{array}$ & 360 & 99 & {$[40]$} \\
\hline 6. & $\begin{array}{c}\mathrm{Co} / \mathrm{Fe}-\mathrm{g}-\mathrm{C}_{3} \mathrm{~N}_{4} / \\
\mathrm{MOFs}\end{array}$ & Hydrothermal method & Rhodamine B & $\mathrm{UV} / \mathrm{Vis}$ & 30 & 99 & [12] \\
\hline 7. & $\mathrm{Fe}-\mathrm{C}_{3} \mathrm{~N}_{4} / \mathrm{Ag}_{2} \mathrm{CO}_{3}$ & Hydrothermal method & Rhodamine B & $\begin{array}{l}\text { Visible } \\
\text { light }\end{array}$ & 180 minutes & 97 & This work \\
\hline
\end{tabular}

among electrons in the $\mathrm{CB}$ of $\mathrm{Ag}_{2} \mathrm{WO}_{4}$ and $\mathrm{VB}$ holes of $\mathrm{Fe}$ $\mathrm{CN}$, ultimately decreasing the charge carrier's recombination within the $\mathrm{Fe}-\mathrm{CN}$ and $\mathrm{Ag}_{2} \mathrm{WO}_{4}$ heterojunction. The $\mathrm{e}^{-}$ in the $\mathrm{CB}$ of $\mathrm{Fe}-\mathrm{CN}$ becomes trapped by the oxygen present on the surface of the composite, forming $\bullet \mathrm{O}^{2-}$. Moreover, holes accumulated in the $\mathrm{CB}$ of $\mathrm{Ag}_{2} \mathrm{WO}_{4}$ react with water molecules, producing hydroxyl radicals. The generated $\bullet \mathrm{OH}$ and $\bullet \mathrm{O}^{2-}$ radicals then participate in the degradation process. These characteristic features of the doped ternary heterostructure lead to the enhancement of photocatalytic degradation instead of individual and binary components. The catalyst Fe-CN-AW showed $97 \%$ degradation under sunlight. A comparison of doped graphitic carbon nitridebased ternary composites is shown in Table 3.

\section{Reusability}

Keeping optimal conditions specified for all three catalysts, stability of all photocatalysts was confirmed by utilizing catalysts continually in 5 consecutive runs for ensuring field application. The catalysts were separated through centrifugation from the treated RhB solution, and distilled water was used for rinsing thrice. Then, samples were dried at $70^{\circ} \mathrm{C}$ utilizing an electric oven. All catalysts were weighed after each catalytic recycle and inspected for their efficiency of $\mathrm{RhB}$ removal. Reusability trials were conducted at optimized conditions for each catalyst in a time duration of two hours for all composites. No considerable catalytic activity loss was detected even after 5 experimental runs, with a minimal 
reduction after the fifth run, as shown in Figure 10(b). Experimental results showed that the Fe-CN-AW ternary heterojunction has high mechanical stability and reusability.

\section{Conclusions}

The Fe-CN-AW is a novel ternary heterojunction that shows a remarkable result for organic dye degradation. A simple hydrothermal method was employed for the fabrication of the iron-doped ternary photocatalyst. The ternary nanocomposite exhibited exceptional rhodamine B degradation, underneath solar light irradiation. The Fe-CN-AW showed 97\% RhB degradation in two hours. The improved photocatalytic efficiency was accredited to the construction of a ternary heterojunction formed because of Fe doping and coupling of graphitic carbon nitride and silver tungstate. The prominent characteristics of all components were present in the ternary heterojunction, with doping further suppressing the recombination of electrons and holes. The catalysts are very stable and show a minimal reduction in efficiency even after five repeated experiments.

\section{Data Availability}

The data used to support the findings of this study are included within the article; additional information/data will be made available upon request.

\section{Conflicts of Interest}

The authors declare no conflicts of interest.

\section{Acknowledgments}

The authors thank Taif University for the generous financial support by the Taif University Researchers Supporting Project, no. (TURSP-2020/90), Taif University, Taif, Saudi Arabia.

\section{References}

[1] E. M. Pala, "Ultrastructural deformities in the scales of Cyprinus carpio inhabiting two government-sponsored fish farms in north-east India contaminated by municipal wastes and other pollutants," Microscopy and Microanalysis, vol. 24, no. 6, pp. 729-733, 2018.

[2] R. Das, "Application photocatalysis for treatment of industrial waste water-a short review," OALib, vol. 1, no. 5, pp. 1-17, 2014.

[3] Y. Deng and R. Zhao, "Advanced oxidation processes (AOPs) in wastewater treatment," Current Pollution Reports, vol. 1, no. 3, pp. 167-176, 2015.

[4] M. O. Barbosa, N. F. F. Moreira, A. R. Ribeiro, M. F. R. Pereira, and A. M. T. Silva, "Occurrence and removal of organic micropollutants: an overview of the watch list of EU Decision 2015/495," Water Research, vol. 94, pp. 257-279, 2016.

[5] J. Fu, "g-C3N4-based heterostructured photocatalysts," Advanced Energy Materials, vol. 8, no. 3, pp. 170-503, 2018.

[6] K. C. Devarayapalli, S. V. Prabhakar Vattikuti, T. V. Madhukar Sreekanth, P. Chidanandha Nagajyothi, and J. Shim, "Pyrolysis synthesized g-C $3 \mathrm{~N}$ 4/Nb 2 O 5 nanocomposite for enhanced photocatalytic activity under white LED light irradiation," Chemistry, vol. 4, no. 45, pp. 13250-13258, 2019.

[7] A. Habibi-Yangjeh and M. Mousavi, "Deposition of CuWO 4 nanoparticles over g-C $3 \mathrm{~N}$ 4/Fe $3 \mathrm{O} 4$ nanocomposite: novel magnetic photocatalysts with drastically enhanced performance under visible-light," Advanced Powder Technology, vol. 29, no. 6, pp. 1379-1392, 2018.

[8] S. V. P. Vattikuti, B. P. Reddy, C. Byon, and J. Shim, "Carbon/ $\mathrm{CuO}$ nanosphere-anchored g-C3N4 nanosheets as ternary electrode material for supercapacitors," Journal of Solid State Chemistry, vol. 262, pp. 106-111, 2018.

[9] K. C. Devarayapalli, K. Lee, N. D. Nam, S. V. P. Vattikuti, and J. Shim, "Microwave synthesized nano-photosensitizer of CdS $\mathrm{QD} / \mathrm{MoO} 3-\mathrm{OV} / \mathrm{g}-\mathrm{C} 3 \mathrm{~N} 4$ heterojunction catalyst for hydrogen evolution under full-spectrum light," Ceramics International, vol. 46, no. 18, pp. 28467-28480, 2020.

[10] S. V. P. Vattikuti, P. A. K. Reddy, J. Shim, and C. Byon, "Visible-light-driven photocatalytic activity of $\mathrm{SnO} 2-\mathrm{ZnO}$ quantum dots anchored on g-C3N4 nanosheets for photocatalytic pollutant degradation and $\mathrm{H} 2$ production," ACS Omega, vol. 3, no. 7, pp. 7587-7602, 2018.

[11] J. Huang, "Ultrathin Ag2WO4-coated P-doped g-C3N4 nanosheets with remarkable photocatalytic performance for indomethacin degradation," Journal of Hazardous Materials, vol. 392, p. 122355, 2020.

[12] P. Liu, "Co/Fe co-doped porous graphite carbon derived from metal organic framework for microelectrolysis-Fenton catalytic degradation of Rhodamine B," Journal of Environmental Chemical Engineering, vol. 9, no. 5, Article ID 105924, 2021.

[13] S. Kumar, "Visible light-assisted photodegradation by silver tungstate-modified magnetite nanocomposite material for enhanced mineralization of organic water contaminants," Applied Nanoscience, vol. 10, pp. 1-15, 2019.

[14] J. Chen, "Fabrication of hierarchical sheet-on-sheet WO3/gC3N4 composites with enhanced photocatalytic activity," Journal of Alloys and Compounds, vol. 777, pp. 325-334, 2019.

[15] P. Praus, "Graphitic carbon nitride: synthesis, characterization and photocatalytic decomposition of nitrous oxide," Materials Chemistry and Physics, vol. 193, pp. 438-446, 2017.

[16] K. Dai, "A facile fabrication of plasmonic g-C3N4/Ag2WO4/ Ag ternary heterojunction visible-light photocatalyst," $M a$ terials Chemistry and Physics, vol. 177, pp. 529-537, 2016.

[17] S. Tonda, "Fe-doped and-mediated graphitic carbon nitride nanosheets for enhanced photocatalytic performance under natural sunlight," Journal of Materials Chemistry, vol. 2, no. 19, pp. 6772-6780, 2014.

[18] T. Li, "Mechanisms for highly efficient mineralization of bisphenol A by heterostructured Ag2WO4/Ag3PO4 under simulated solar light," ACS Sustainable Chemistry \& Engineering, vol. 7, no. 4, pp. 4177-4185, 2019.

[19] P. Raizada, A. A. P. Khan, and P. Singh, "Construction of carbon nanotube mediated Fe doped graphitic carbon nitride and Ag3VO4 based Z-scheme heterojunction for $\mathrm{H} 2 \mathrm{O} 2$ assisted 2, 4 dimethyl phenol photodegradation," Separation and Purification Technology, vol. 247, p. 116957, 2020.

[20] B. Zhu, "Fabrication and photocatalytic activity enhanced mechanism of direct Z-scheme g-C3N4/Ag2WO4 photocatalyst," Applied Surface Science, vol. 391, pp. 175-183, 2017.

[21] S. Honary, "Green synthesis of silver nanoparticles induced by the fungus Penicillium citrinum," Tropical Journal of Pharmaceutical Research, vol. 12, no. 1, pp. 7-11, 2013.

[22] K. Devarayapalli, "Mesostructured g-C3N4 nanosheets interconnected with V2O5 nanobelts as electrode for 
coin-cell-type-asymmetric supercapacitor device," Materials Today Energy, vol. 21, p. 100699, 2021.

[23] M. U. Rahman, "Solar driven photocatalytic degradation potential of novel graphitic carbon nitride based nano zerovalent iron doped bismuth ferrite ternary composite," Optical Materials, vol. 120, p. 111408, 2021.

[24] X. Wang, "Recyclable nanoscale zero valent iron doped g-C3N4/MoS2 for efficient photocatalysis of $\mathrm{RhB}$ and $\mathrm{Cr}$ (VI) driven by visible light," ACS Sustainable Chemistry \& Engineering, vol. 4, no. 7, pp. 4055-4063, 2016.

[25] N. Nadeem, "Degradation of reactive dye using heterogeneous photo-Fenton catalysts: $\mathrm{ZnFe} 2 \mathrm{O} 4$ and GO-ZnFe2O4 composite," Materials Research Express, vol. 7, no. 1, p. 015519, 2020.

[26] N. Tahir, "Fabrication of visible light active Mn-doped $\mathrm{Bi} 2 \mathrm{WO} 6-\mathrm{GO} / \mathrm{MoS} 2$ heterostructure for enhanced photocatalytic degradation of methylene blue," Environmental Science and Pollution Research, pp. 1-16, 2021.

[27] C. V. Reddy, "Mn-doped $\mathrm{ZrO} 2$ nanoparticles prepared by a template-free method for electrochemical energy storage and abatement of dye degradation," Ceramics International, vol. 45, no. 12, pp. 15298-15306, 2019.

[28] R. Saher, "Sunlight-driven photocatalytic degradation of rhodamine B dye by $\mathrm{Ag} / \mathrm{FeW} 4 / \mathrm{gC} 3 \mathrm{~N} 4$ composites," International journal of Environmental Science and Technology, vol. 18, no. 4, pp. 927-938, 2021.

[29] J. F. Moulder, Handbook of X-Ray Photoelectron Spectroscopy, pp. 230-232, Perkin-Elmer Corporation, Waltham, MA, UA, 1995.

[30] B. Yu, "Functionalized graphene oxide/phosphoramide oligomer hybrids flame retardant prepared via in situ polymerization for improving the fire safety of polypropylene," RSC Advances, vol. 4, no. 60, pp. 31782-31794, 2014.

[31] P. Li, "Carboxyl groups on g-C3N4 for boosting the photocatalytic U (VI) reduction in the presence of carbonates," Chemical Engineering Journal, vol. 414, pp. 12-88, 2021.

[32] R. Ahmad, "Photocatalytic systems as an advanced environmental remediation: recent developments, limitations and new avenues for applications," Journal of Environmental Chemical Engineering, vol. 4, no. 4, pp. 4143-4164, 2016.

[33] A. Rafiq, "Photocatalytic degradation of dyes using semiconductor photocatalysts to clean industrial water pollution," Journal of Industrial and Engineering Chemistry, vol. 97, 2021.

[34] M. Abdellah, "Photocatalytic decolorization of methylene blue using TiO2/UV system enhanced by air sparging," Alexandria engineering journal, vol. 57, no. 4, pp. 3727-3735, 2018.

[35] N. Nadeem, "Improved photocatalytic degradation of dye using coal fly ash-based zinc ferrite (CFA/ZnFe2O4) composite," International journal of Environmental Science and Technology, pp. 1-16, 2021.

[36] I. D. Tunç, "Growth of $\mathrm{ZnO}$ nanowires on carbon fibers for photocatalytic degradation of methylene blue aqueous solutions: an investigation on the optimization of processing parameters through response surface methodology/central composite design," Ceramics International, vol. 46, no. 6 , pp. 7459-7474, 2020.

[37] S. Mortazavian, A. Saber, and D. E. James, "Optimization of photocatalytic degradation of Acid Blue 113 and Acid Red 88 textile dyes in a UV-C/TiO2 suspension system: application of response surface methodology (RSM)," Catalysts, vol. 9, no. 4, pp. 300-360, 2019.

[38] P. Raizada, "Visible light assisted photodegradation of 2, 4dinitrophenol using Ag2CO3 loaded phosphorus and sulphur co-doped graphitic carbon nitride nanosheets in simulated wastewater," Arabian Journal of Chemistry, vol. 13, no. 1, pp. 3196-3209, 2020.

[39] A. Uddin, "Hydrothermal synthesis of $3 \mathrm{D} / 2 \mathrm{D}$ heterojunctions of ZnIn2S4/oxygen doped g-C3N4 nanosheet for visible light driven photocatalysis of 2, 4-dichlorophenoxyacetic acid degradation," Journal of Alloys and Compounds, vol. 845, p. $156206,2020$.

[40] P. Raizada, "Fabrication of Ag3VO4 decorated phosphorus and sulphur co-doped graphitic carbon nitride as a highdispersed photocatalyst for phenol mineralization and E. coli disinfection," Separation and Purification Technology, vol. 212, pp. 887-900, 2019. 